\title{
Vulnerabilidad socioeducativa y económica de adolescentes y jóvenes en cinco municipios de la RACS
}

Marieliz Belinda Rodríguez Vásquez

Este artículo está basado en el estudio "Situación socioeducativa y económica de la juventud en contexto de vulnerabilidad" realizado por Ethel Martínez Webster en cinco municipios litorales de la Región Autónoma Caribe Sur (RACS): Bluefields, Corn Island, Desembocadura de la Cruz de Río Grande, Kukra Hill y Laguna de Perlas. ${ }^{1}$

Los temas de análisis fueron las condiciones sociales, económicas y culturales en que viven adolescentes y jóvenes entre 15 y 24 años de edad, de acuerdo a las variables identidad, relación familiar, educación, salud, relación laboral, migración, participación comunitaria, organización juvenil, tiempo libre, valores y economía familiar.

El estudio también identifica la situación de riesgo social en que viven adolescentes y jóvenes de acuerdo a seis indicadores ${ }^{2}$ y clasifica estas situaciones en rangos que van desde riesgo muy alto hasta riesgo bajo. Analiza además el escenario comunitario identificando las oportunidades y potencialidades laborales de los municipios e incluye un análisis acerca de cómo potenciar estas oportunidades a través de programas con adolescentes y jóvenes.

Este artículo comienza analizando los resultados del estudio a partir de un marco conceptual de vulnerabilidad propuesto por la Comisión Económica para América Latina y el Caribe (CEPAL) que identifica las fuentes que generan la vulnerabilidad de jóvenes desde tres dimensiones - vital, institucional y de inserción socioeconómica (Gráfico 1)-y valora oportunidades y agentes facilitadores que pueden disminuir esta vulnerabilidad.
El informe de la investigación concluye con algunas recomendaciones que pueden guiar futuras intervenciones y valorar la pertinencia de aquéllas que ya se están realizando con adolescentes y jóvenes de los municipios estudiados.

\section{DIMENSION VITAL}

En el marco de la vunerabilidad juvenil, la dimensión vital incluye la maduración psicosocial incompleta que implica la capacidad del manejo de habilidades cognitivas y emocionales de manera congruente, lo cual posibilita la toma de decisiones y el control de los impulsos, así como resistir a la presión social o calcular los riesgos de cualquier decisión peligrosa ${ }^{3}$. La dimensión vital también incluye la incertidumbre sobre la identidad (quién soy), la inserción social (cómo me integro en esta sociedad) y la inexperiencia que tipifica esta etapa de la vida (cómo asumo roles de adulto si no tengo la experiencia).

\section{Identidad}

Sentirse parte de una colectividad, auto reconocerse y ser reconocido dentro de determinados contextos es una necesidad básica del ser humano (López, 2012), por lo que estas características pueden significar activos de adolescentes y jóvenes para enfrentar las adversidades.

Para este estudio se exploró identidades y sentido de pertenencia de adolescentes y jóvenes, partiendo de algunas variables: lugar de nacimiento, lengua materna predominante y el orgullo de ser costeño. (Tabla 1)

l Este estudio fue comisionado por el Programa Educación para el Éxito de FADCANIC y USAID. La encuesta, grupos focales y entrevistas que hacen parte del estudio fueron realizados entre julio y setiembre de 2012.

2 Para efectos del estudio, se define que un joven está en riesgo social si enfrenta cualquiera de las seis situaciones siguientes: (1) es un fumador frecuente, (2) es bebedor de alcohol frecuente, (3) prueba drogas, (4) participa en una pandilla, (5) ha estado deprimido y pensado en el suicidio, y (6) ha sido hospitalizado por intoxicación.

3 Refiere a temas como autoestima, toma de decisiones, comunicación asertiva, plan de vida y sexualidad. 


\section{Gráfico 1. Fuentes de la Vulnerabilidad Juvenil Actual}

\section{Dimensión \\ Vital \\ INESTABILIDAD}
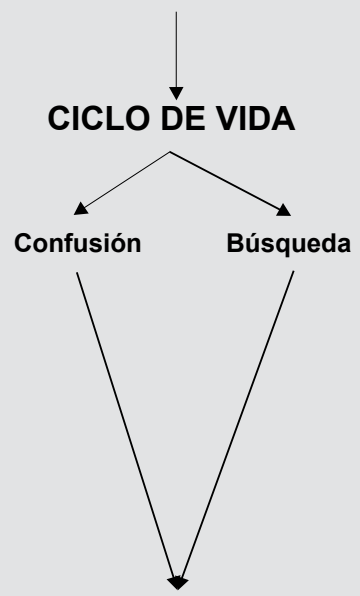

Decisiones CRuciales
Dimensión

Institucional

ASIMETRÍA Y CAUTELA

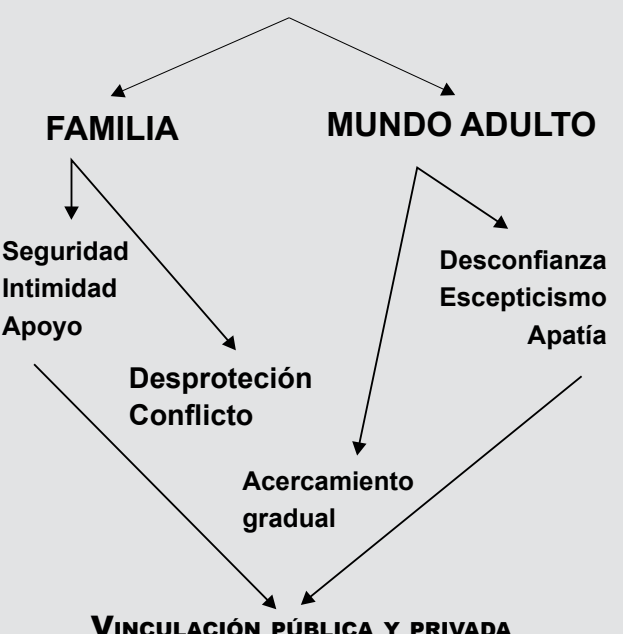

\section{Dimensión Inserción Socioeconómica ASIMETRÍA Y CAUTELA}

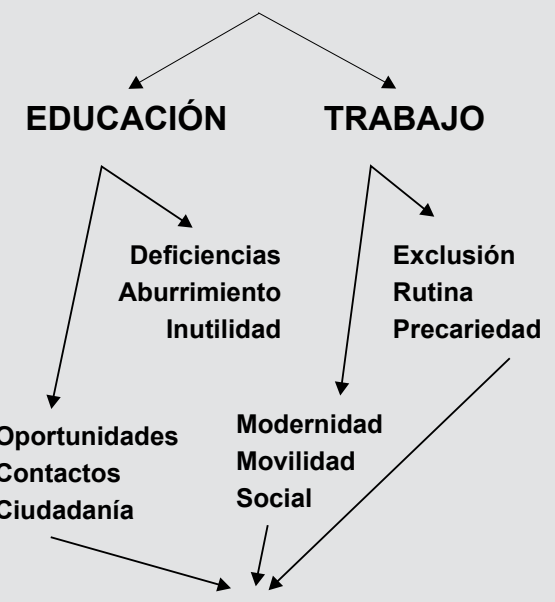

Confianza versus Frustración

Fuente: Basado en CELADE 2001. Rodríguez J. Informe vulnerabilidad y grupos vulnerables: un marco de referencia conceptual mirando a jóvenes.

Tabla 1. Características identitarias de adolescentes y jóvenes de cinco municipios de la RACS (en porcentajes)

\begin{tabular}{|c|c|c|c|c|c|c|}
\hline Características & Bluefields & Corn Island & $\begin{array}{c}\text { Desembocadura } \\
\text { de Río Grande }\end{array}$ & Kukra Hill & $\begin{array}{l}\text { Laguna de } \\
\text { Perlas }\end{array}$ & Total \\
\hline \multicolumn{7}{|l|}{ Lugar de nacimiento } \\
\hline Originario del municipio & 95 & 100 & 100 & 100 & 96 & 98 \\
\hline Nacimiento urbano & 80 & 90 & 24 & 92 & 68 & 71 \\
\hline \multicolumn{7}{|l|}{ Origen Étnico } \\
\hline Afrodescendiente & 23 & 63 & 5 & 24 & 61 & 35 \\
\hline Indígena & 11 & 24 & 96 & 11 & 18 & 32 \\
\hline Mestizo & 66 & 13 & 1 & 64 & 21 & 33 \\
\hline \multicolumn{7}{|l|}{ Idioma } \\
\hline Creole & 23 & 56 & 6 & 39 & 52 & 35 \\
\hline Mískitu & 6 & 29 & 57 & 12 & 14 & 24 \\
\hline Español & 67 & 15 & 0 & 49 & 22 & 31 \\
\hline $\begin{array}{l}\text { Otras Lenguas } \\
\text { (Garífuna, Ulwa, Mayagna, Rama) }\end{array}$ & 4 & 0 & 40 & 0 & 12 & 11 \\
\hline \multicolumn{7}{|l|}{ Orgullo de ser costeña o costeño } \\
\hline Mujeres & 91 & 82 & 60 & 97 & 93 & 85 \\
\hline Hombres & 89 & 83 & 67 & 96 & 90 & 85 \\
\hline
\end{tabular}

Fuente: Elaboración propia basado en datos de FADCANIC 2013. Martínez, E. Informe Final Estudio de situación socioeducativaeconómica de la juventud en contexto de vulnerabilidad en cinco municipios de la Región Autónoma del Atlántico Sur. 
Tabla 2. Prácticas ligadas a la sexualidad y reproducción de adolescentes y jóvenes de cinco municipios de la RACS (en porcentajes)

\begin{tabular}{|c|c|c|c|c|c|c|c|c|c|c|}
\hline \multirow[t]{2}{*}{ Municipios } & \multicolumn{2}{|c|}{$\begin{array}{l}\text { Relaciones } \\
\text { Sexuales }\end{array}$} & \multicolumn{2}{|c|}{$\begin{array}{c}\text { Uso de Métodos } \\
\text { Anticonceptivos últimos } 6 \\
\text { meses }\end{array}$} & \multicolumn{2}{|c|}{$\begin{array}{l}\text { Uso de condón en } \\
\text { últimos } 6 \text { meses }\end{array}$} & \multicolumn{2}{|c|}{$\begin{array}{l}\text { Relaciones de Pareja } \\
\text { estable }\end{array}$} & \multicolumn{2}{|c|}{$\begin{array}{l}\text { Tiene uno } \\
\text { o más hijos }\end{array}$} \\
\hline & Mujeres & Hombres & Mujeres & Hombres & Mujeres & Hombres & Mujeres & Hombres & Mujeres & Hombres \\
\hline Bluefields & 84 & 95 & 88 & 73 & 38 & 68 & 26 & 19 & 30 & 17 \\
\hline Corn Island & 90 & 93 & 69 & 73 & 19 & 57 & 34 & 15 & 34 & 26 \\
\hline $\begin{array}{l}\text { Desembocadura } \\
\text { de Río Grande }\end{array}$ & 91 & 90 & 88 & 93 & 22 & 70 & 29 & 22 & 57 & 31 \\
\hline Kukra Hill & 64 & 78 & 83 & 95 & 4 & 79 & 33 & 15 & 36 & 8 \\
\hline $\begin{array}{l}\text { Laguna de } \\
\text { Perlas }\end{array}$ & 86 & 79 & 64 & 85 & 12 & 73 & 13 & 4 & 43 & 10 \\
\hline Total & 83 & 87 & 78 & 84 & 19 & 69 & 27 & 15 & 40 & 18 \\
\hline
\end{tabular}

Fuente: Elaboración propia basado en datos de FADCANIC 2013.

\section{Decisiones cruciales}

\section{Sexualidad y familia}

La conformación de su propia familia es otra de las decisiones cruciales que toman hombres y mujeres adolescentes y jóvenes. Entre más joven se toma esta decisión más se limita la acumulación de activos para su desarrollo personal y profesional. En el estudio, donde el $22 \%$ tenía o había tenido relaciones de pareja estable 4 , se observa variaciones por edad. Las relaciones de noviazgo se establecían entre los quince y diecinueve años; después descienden incrementándose las relaciones de pareja (acompañados, casados) a partir de los veinte años.

\section{Maternidad y paternidad tempranas: un riesgo}

Según el informe de desarrollo humano (PNUD, 2011:106), la maternidad y la paternidad adolescentes influyen negativamente en los logros educativos de la población adolescente y juvenil. Si bien adolescentes y jóvenes en general no logran alcanzar los años de escolaridad acorde con su edad, quienes tienen hijos e hijas presentan mayores rezagos educativos (ENAJINDH, 2009). Ello limita sus capacidades y la posibilidad de evitar la cadena intergeneracional de desigualdades y privaciones. En este estudio, casi el 29\% de adolescentes y jóvenes participantes ya había procreado al menos una vez.

\section{Mayor vulnerabilidad en la maternidad}

Cabe mencionar que, del total de jóvenes que tenía vástagos, el $28 \%$ era menor de veinte años y el $66 \%$ eran mujeres. Esto generalmente está relacionado con los roles de género que asignan a las mujeres la maternidad temprana y el cuido del infante, lo que puede llevar a rezagos más pronunciados en las mujeres que son madres que en los varones adolescentes y jóvenes. El municipio Desembocadura de Río Grande, con la mayoría de su población indígena ulwa y miskita destaca en este aspecto, por ser el municipio en donde casi la mitad de participantes en el estudio (42\%) ya había procreado, mientras Kukra Hill presenta la menor proporción (19\%).

\section{Uso de anticonceptivos}

El uso de métodos anticonceptivos fue alto en esta población encuestada. Cuatro de cada cinco dijo haberlo usado en los últimos seis meses antes de la encuesta, con mayor uso en hombres $(84 \%)$ que en mujeres $(78 \%)$.

$4 \quad$ Incluye adolescentes y jóvenes que dijeron estar casados o unidos, con viudez o separado. 
A diferencia de otros estudios (ENDESA 2011/12, UNFPA 2013), el uso del condón en esta población es considerablemente alta: $69 \%$ en los varones y $19 \%$ en mujeres. Esto puede reflejar el impacto positivo de programas educativos y campañas de promoción y comunicación que se han realizado en la región, por lo que es importante seguir impulsando programas similares tomando en cuenta las lecciones aprendidas.

En resumen, en esta población existe una iniciación sexual, crecientemente desligada de una unión estable y de propósitos reproductivos, que conlleva a una mayor alternancia de parejas sexuales y aumenta los riesgos de adquirir infecciones de transmisión sexual. Aunque el estudio no ahonda en esta situación, los datos del MINSA proporcionados en el marco de referencia del estudio reflejan altas tasas de incidencia de infecciones de trasmisión sexual en la población entre quince y veinticuatro años (MINSA, 2009).

Es importante tomar en cuenta que la desvinculación entre sexualidad y reproducción, en el plano subjetivo, puede conducir a un incremento de la fecundidad no deseada o fuera de una unión estable y generar la formación de núcleos familiares uniparentales (Giddens, 1991). Esto es relevante en este estudio, porque los mismos adolescentes y jóvenes lo han vivido (59\% no vive con ambos progenitores), además, lo reproducen en su ciclo de vida $(20 \%$ de jóvenes que tienen hijos no viven con ellos). No vivir con los hijos e hijas es mas prevalente en jóvenes varones (70\%) que en las mujeres jóvenes (30\%), traduciéndose también esto en una mayor vulnerabilidad para sus vástagos.

Los programas dirigidos a esta población deben estar orientados a mejorar las competencias para la toma de decisiones conscientes, responsables, con información

60
Gráfico 2 • Jóvenes en pareja estable vs. Jóvenes con hijos (en porcentajes)

Tienen pareja $\quad$ Tienen hijos

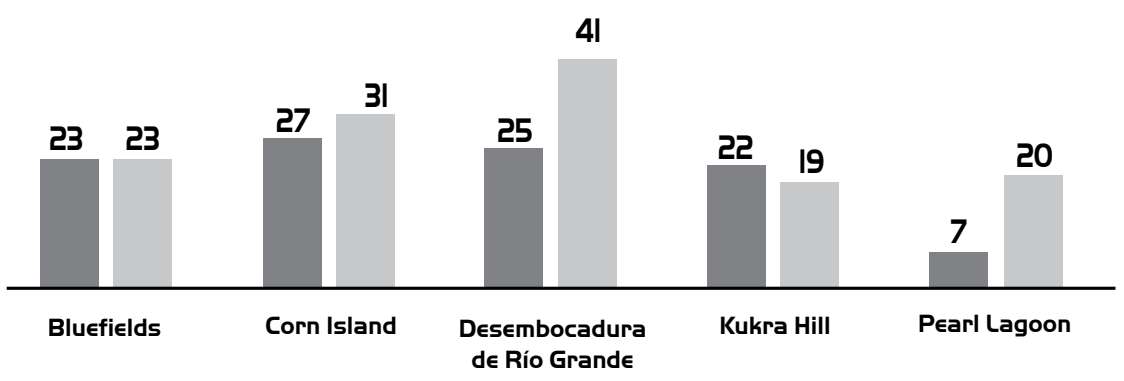

Fuente: Elaboración propia basado en datos de FADCANIC 2013.

\section{Gráfico 3 • Jóvenes progenitoers que no viven con hijos (en porcentajes) \\ Mujeres Hombres}

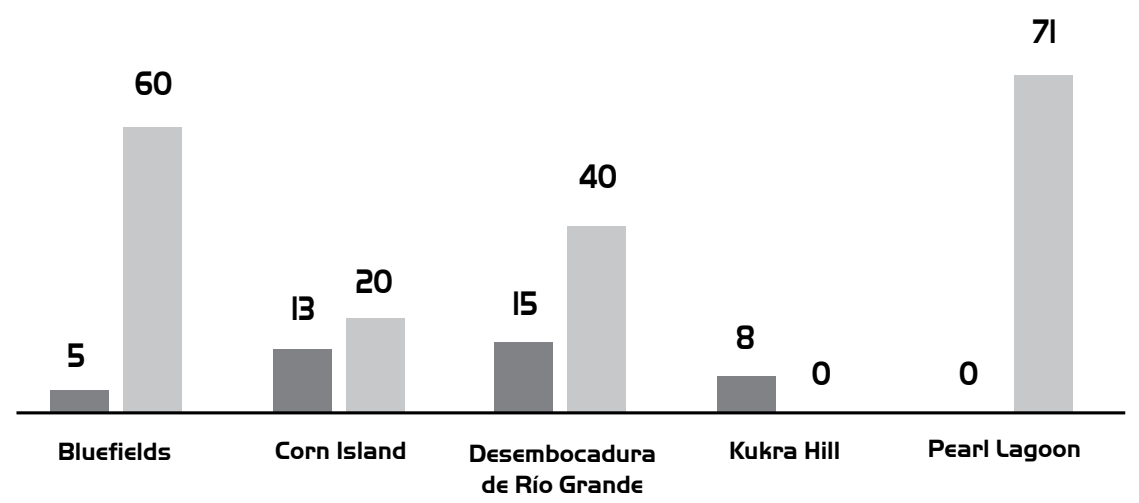

Fuente: Elaboración propia basado en datos de FADCANIC 2013. adecuada y un mejor acceso a los métodos anticonceptivos y a la importancia de la maternidad y paternidad responsables.

En su marco de referencia, el estudio de Martínez incluyó estadísticas del MINSA para los cinco municipios. Según los datos registrados por el SILAIS RACS para el primer semestre del periodo comprendido entre 2008 
y 2011, el promedio de embarazos adolescentes (menor de 19 años) fue de $37.9 \%$ de todos los embarazos registrados en la región. Durante ese mismo periodo, los embarazos de niñas y adolescentes en edades de 10 a 14 años, correspondían a $8.24 \%$ de todos los embarazos adolescentes. Valorar el índice de abuso sexual en esta población es urgente.

\section{Salud física, emocional y autocuido}

En el estudio se identificó una alta morbilidad, ya que casi tres de cada cuatro jóvenes habían sido hospitalizados $(72 \%)$ por cirugía mayor, menor y por otras causas. Al mismo tiempo, $48 \%$ de esta población manifestó haber sido atendida en un centro de salud, clínica u hospital por causa de enfermedades común. Otro $12 \%$ de adolescentes y jóvenes fue atendido debido a lesiones por accidente. Cabe destacar que las lesiones por violencia, intoxicación alcohólica y otras drogas, y las infecciones de transmisión sexual fueron también causas de morbilidad en la juventud de estos municipios representando en su conjunto a $7 \%$ de las causas de atención médica. También llama la atención que es mínima la proporción con infecciones y enfermedades de transmisión sexual $(0 \%$ de ITS y $2 \%$ de ETS), sobre todo en mujeres, al contrario de las estadísticas del MINSA las cuales informan que Bluefields, Corn Island y la Desembocadura tienen alta incidencia de ETS y son las mujeres quienes más acuden a estos servicios.

El estudio indagó también acerca de dos situaciones relativas a la salud mental que podrían indicar mayor vulnerabilidad en esta población. Entre los cinco municipios, el 39\% ha presentado depresión en los últimos doce meses, siendo más frecuente en las mujeres (44\%) que en los hombres (35\%).

\section{Gráfico 4 • ¿Motivo por el cual recibió atención en salud (en porcentajes)}

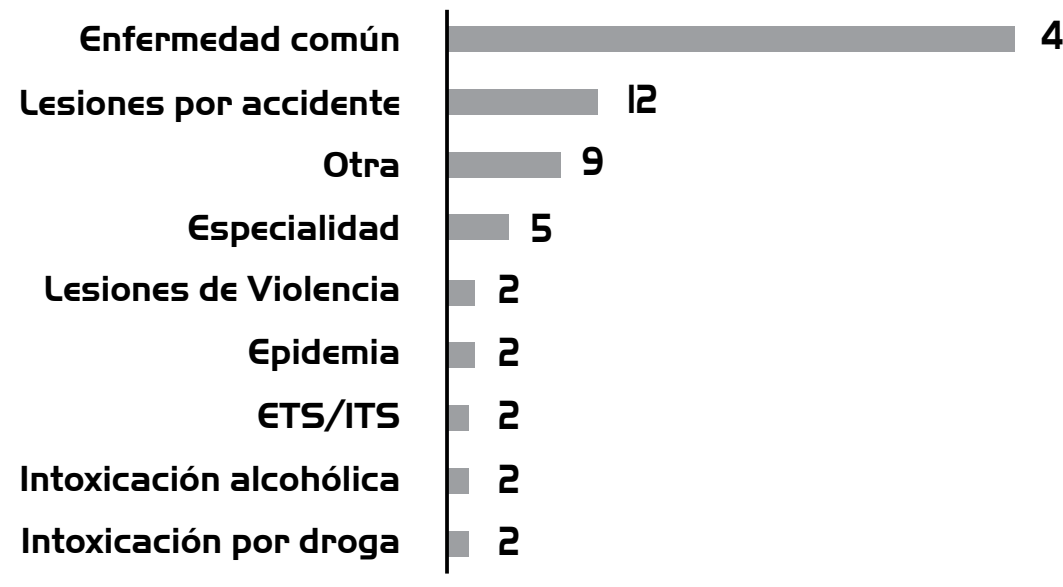

Fuente: Elaboración propia basada en datos de FADCANIC 2013.

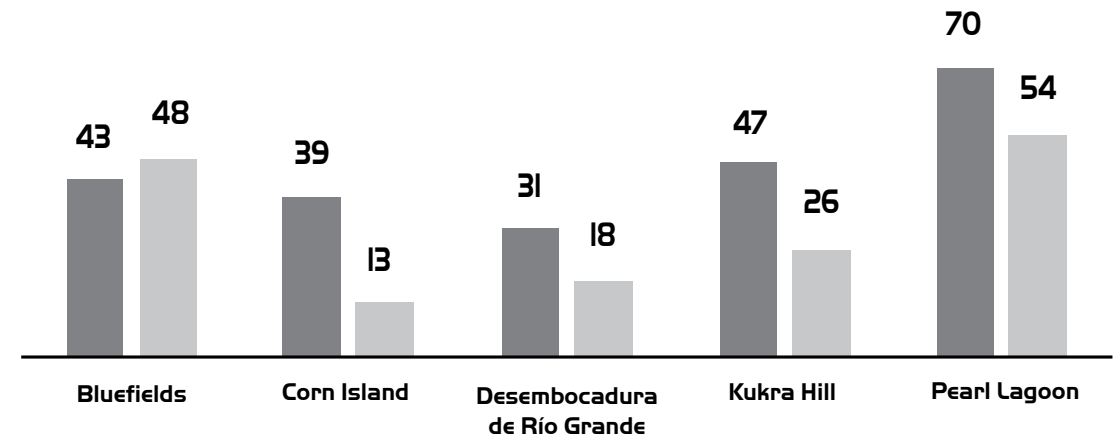

Fuente: Elaboración propia basado en datos de FADCANIC 2013.

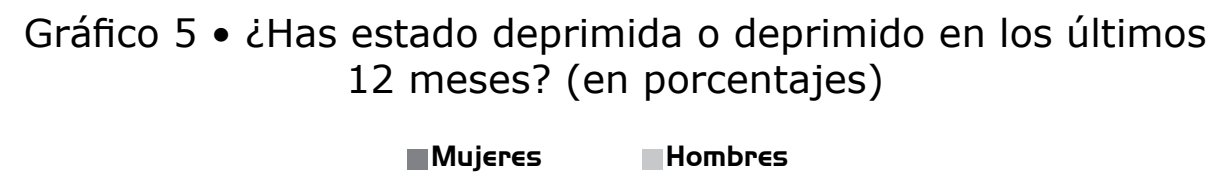

70

La frecuencia de ideas suicidas también es mayor en las mujeres $(23 \%)$ que en los hombres (17\%). Ambos problemas son muy importantes en esta población. Dado que la juventud es una etapa vital, caracterizada por un proceso transitorio y complejo entre la niñez y adultez, las personas jóvenes son más vulnerables a determinadas situaciones psicosociales. Éstas pueden desencadenar, en algún momento de la vida, conductas inestables y alteración 
Gráfico 6 • ¿Alguna vez has pensado en el siucidio? (en porcentajes)

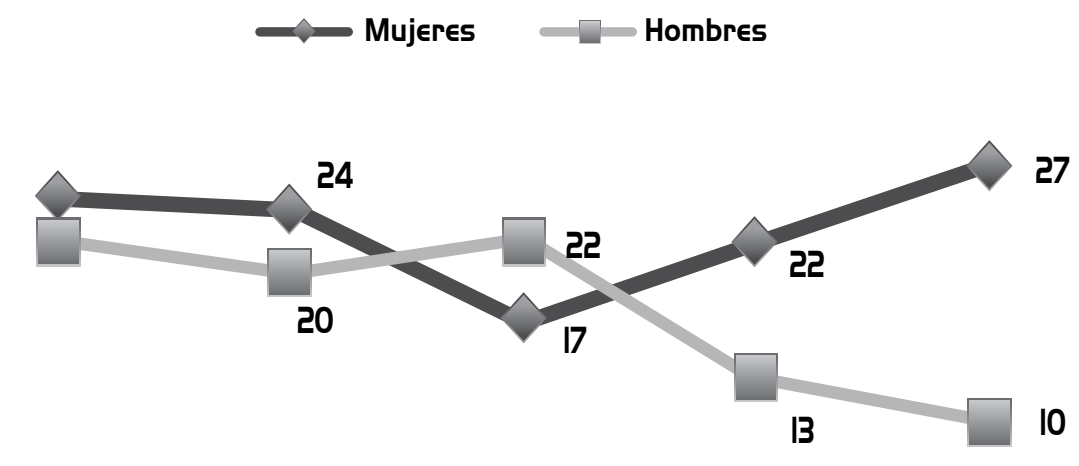

Bluefields
Kukra Hill

Pearl Lagoon
Desembocadura de Río Grande

Fuente: Elaboración propia basado en datos de FADCANIC 2013.

de la salud mental limitando la plena comunicación y la participación social activa, y causando sufrimiento humano e incapacidad.

Es por esto que se hace necesario definir estrategias para trabajar la depresión e ideas suicidas desde las aulas de clase, y programas comunitarios para los que están fuera de la escuela. Pero se debe partir de capacitar al personal docente y comunitario, de tal manera que desarrollen competencias para la identificación de signos y síntomas. La docencia y todo personal que trabaja con adolescentes y jóvenes también debe ser capacitada sobre el abordaje inicial. Esto para que se refiera adecuadamente y para que se puedan abordar las raíces del problema en la familia y la comunidad.

\section{Consumo de alcohol}

En el medio sociocultural de la Región Autónoma del Caribe Sur, el alcohol es una droga muy extendida, bastante arraigada en las costumbres y de amplia aceptación y valoración social. Estas circunstancias han ido favoreciendo tanto el desarrollo de conductas de consumo excesivas, como la existencia de bebedores cada vez más jóvenes.

Del total de la población participante en el estudio, el 62\% habia consumido licor. Tres de cada cuatro varones jóvenes lo consumían y casi la mitad de las mujeres jóvenes. Estas cifras son altas comparadas con otros estudios de consumo en estudiantes de secundaria que han reportado proporciones menores: 32.5\% (OEA, 2006) y $52 \%$ (Duarte, 2006).

De forma particular, llama la atención que en Bluefields y Corn Island casi dos de cada tres mujeres habían consumido alcohol al momento del estudio, comparado con Laguna de Perlas, donde solo una de cada tres mujeres jovenes habian consumido alcohol. Kukra Hill y la Desembocadura tuvieron la menor proporción puesto que en estos dos municios sólo una de cada cinco mujeres habia consumido alcohol.

El estudio no proporciona datos sobre el inicio de la práctica, lo cual es muy importante para la intervencion. (Tabla 3.)

\section{Consumo de tabaco y drogas}

El consumo de tabaco también fue significativo. El 29\% de adolescentes y jóvenes fumaba (mas de cuatro de cada diez hombres y 12 por ciento ocho mujeres). Los municipios con mayores proporciones fueron Desembocadura de la Cruz de Río Grande y Bluefields, donde más de la mitad de hombres consumían cigarrillos.

Igual a lo que sucede en el caso del alcohol, la adolescencia es un período crítico para iniciar el consumo del tabaco. La mayoría de adolescentes que comienza a fumar con regularidad se vuelve dependiente, resultando muy difícil la modificación de este comportamiento una vez establecido.

El consumo de drogas ilícitas es otra de las conductas que causan daño a la salud. En el estudio, el 33\% de adolescentes y jóvenes participantes había consumido algún tipo de drogas (marihuana, coca, crack y mezcladas), con mayor consumo en varones $(43 \%)$.

En los municipios de Bluefields, Desembocadura, Corn Island y Pearl Lagoon, entre cuatro y cinco de cada diez adolescentes y jóvenes varones han consumido alguna de estas sustancias o combinadas. 


\section{Tabla 3. Prácticas de riesgo social en adolescentes y jóvenes de cinco municipios de la RACS (en porcentajes)}

\begin{tabular}{|c|c|c|c|c|c|c|c|c|}
\hline \multirow{2}{*}{ Municipios } & \multicolumn{2}{|c|}{ Pandillas* } & \multicolumn{2}{|c|}{ Alcohol } & \multicolumn{2}{|c|}{ Cigarrillos } & \multicolumn{2}{|c|}{ Drogas } \\
\hline & Mujeres & Hombres & Mujeres & Hombres & Mujeres & Hombres & Mujeres & Hombres \\
\hline Bluefields & 25 & 47 & 68 & 84 & 25 & 55 & 27 & 50 \\
\hline Corn Island & 16 & 20 & 63 & 71 & 9 & 29 & 21 & 46 \\
\hline $\begin{array}{l}\text { Desembocadura de } \\
\text { Río Grande }\end{array}$ & 11 & 18 & 18 & 77 & 14 & 65 & 17 & 51 \\
\hline Kukra Hill & 3 & 15 & 20 & 68 & 6 & 19 & 14 & 26 \\
\hline Laguna de Perlas & 0 & 6 & 33 & 70 & 7 & 43 & 23 & 41 \\
\hline Total & 14 & 21 & 40 & 74 & 12 & 42 & 20 & 43 \\
\hline Ambos Sexos & \multicolumn{2}{|c|}{18} & \multicolumn{2}{|c|}{62} & \multicolumn{2}{|c|}{29} & \multicolumn{2}{|c|}{33} \\
\hline
\end{tabular}

*Incluye grupos juveniles organizados en el barrio y pandillas.

Fuente: Elaboración propia basada en datos de FADCANIC 2013.

En las mujeres, la proporción de consumo encontrada fue dos de cada cinco. Esta es una cifra alta comparada con lo que ha sido encontrado en otros estudios en donde el consumo de drogas en estudiantes es menor del $10 \%$.

De forma general, el $99.8 \%$ de los encuestados había practicado o tenía al menos uno de los tres hábitos: fumar, beber licor o consumir drogas; el $26 \%$ del total de encuestados ha practicado los tres hábitos en los últimos doce meses, y el mayor porcentaje (42\%) de éstos corresponde al municipio de Bluefields.

\section{Las pandillas}

Aunque en el estudio se valoró la pertenencia a pandillas como fuente de vulnerabilidad, la proporción no fue muy significativa, ya que solo el $1 \%$ de los varones aseguró pertenecer a una pandilla. Pero cuando se preguntó directamente si ha pertenecido a un grupo juvenil o pandilla, el $21 \%$ de los varones y el $14 \%$ de las mujeres aseguraron haber participado en alguna de estas formas organizativas. El haber includido indistintamente ambos términos, no permite un análisis más minucioso de la situación. Según datos de la División de Asuntos Juveniles de la Policía Nacional, "no hay pandillas de jóvenes en la RAAS; lo que hay son 11 grupos juveniles en situación de riesgo ${ }^{6}$ que en su conjunto incluyen entre 106 a 119 adolescentes de doce y más años de edad".

Esto significa que aunque todavía no se han conformado pandillas se están gestando las condiciones para ese próximo paso, teniendo el sistema una oportunidad de actuar en la prevención de la violencia juvenil antes que la situación llegue a niveles extremos de crimen organizado, tal y como ocurre en El Salvador y Honduras. Se hace necesario un plan multisectorial donde cada actor disponga recursos para invertir en programas de recreación, empleabilidad y de inserción en programas de educación para quienes han quedado rezagados en sus estudios.

\footnotetext{
5 Tomado de informe presentado por el Oficial de Asuntos Juveniles de la RAAS Eleazar Oporta en reunión multisectorial de organizaciones juveniles de Bluefields 2011.

6 Grupos juveniles en situaciones de riesgo son agrupaciones espontáneas que no están organizadas de forma jerárquica y que cometen actos ilegales menores y no delitos graves.
} 


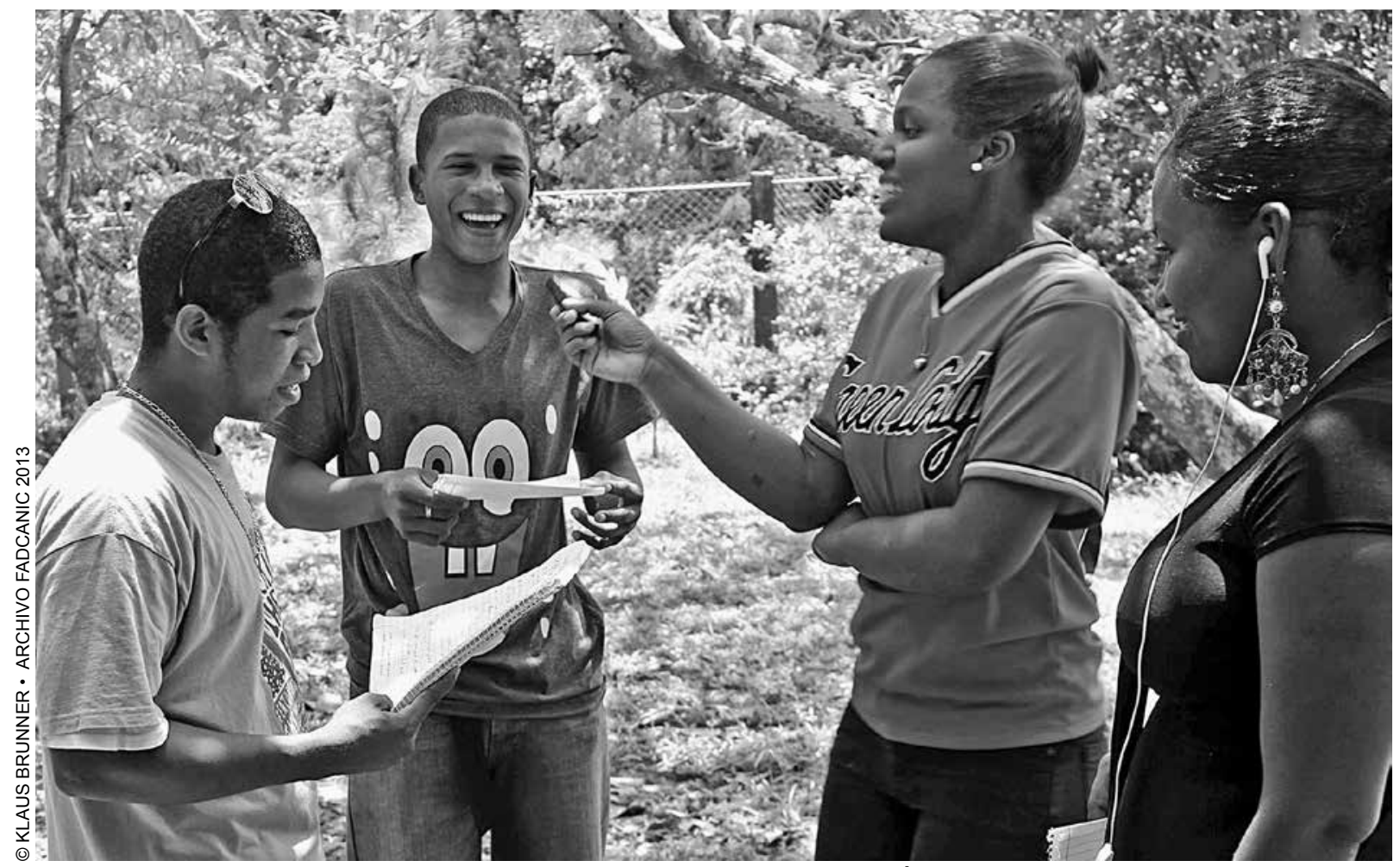

Participantes en el curso de producción de radio y video de EduÉxito en Laguna de Perlas.

Para revertir los procesos de gestación de pandillas juveniles se puede impulsar programas que influyan: en el ámbito personal, con el objetivo de mejorar habilidades para la vida-acrecentar la autoestima, comunicación, proyectos de vida y toma de decisiones; en el ámbito familiar-capacidad para resolver los conflictos, comunicación intrafamiliar, afectividad, utilización de tiempo libre, grupos de pares; y en el medio sociocultural -escuela que motiva interés por el estudio, oportunidades laborales, espacios de recreación y participación. Todo esto también incide en la prevención de la violencia juvenil porque con estas iniciativas, adolescentes y jóvenes se integran en la vida escolar y laboral aprovechando el tiempo libre y de ocio en actividades formativas y recreativas que les alejan de las delictivas.

\section{Actividades recreativas versus prácticas de riesgo}

El consumo de alcohol en la juventud se asocia claramente al tiempo de ocio y a la actividad de grupo; por ello, el patrón del consumo en adolescente es diferente al del adulto; mientras éste bebe con más regularidad y lo hace en grupos y a veces sólo, el joven lo suele hacer concentrándolo en el tiempo de diversión y en el marco del grupo de amigos. Por eso es necesario dirigir esfuerzos para promover la diversión sana, recreativa, fiestas informativas sin licor, ligas deportivas que promuevan los estilos de vida saludable y vigilancia más de cerca de la venta de bebidas alcohólicas a adolescentes. Es necesaria una campaña amplia dirigida a adolescentes y jóvenes, familias, instituciones y comunidad, que promueva la recreación sana, los estilos de vida saludables y visibilice los efectos nocivos del alcohol, cigarrillo y drogas, en el ámbito individual y comunitario.

La escuela es un espacio con grandes potencialidades para la promoción de competencias psicosociales, la educación en salud mental, y para reconocer y orientar, a los estudiantes que lo necesitan, hacia un tratamiento profesional (OMS, 2008). Además, en el estudio, la juventud reconoció que también la escuela forma en valores. Esto requiere, por lo tanto, que en los establecimientos educacionales se implemente estrategias que promuevan el desarrollo armónico de adolescentes y de jóvenes. Para esto es indispensable incorporar determinados valores y conductas: respeto y reconocimiento de la juventud y su cultura, establecer límites claros y adecuados en su relación con los adultos y, principalmente, acoger sus vivencias, inquietudes y dificultades. 


\section{DIMENSIÓN INSTITUCIONAL}

\section{El papel preponderante de la familia}

La familia es considerada como una fuente básica de transmisión de capacidades de las personas para poder sentir emociones y expresarlas, sin que el miedo y la ansiedad las dominen. Aquí se forjan y trasmiten los valores, las reglas, el lenguaje, las tradiciones y la cultura. Además proporciona el patrimonio material que permite a adolescentes y jóvenes sobrevivir y que se inviertan recursos en su desarrollo personal, profesional y como ciudadano. ${ }^{7}$ En las propuestas de políticas se considera a la familia como un factor explicativo del comportamiento individual (CEPAL, 2007). Pero también adolescentes y jóvenes aprenden, ya sea de forma informal o por imitación, algunos códigos culturales y formas de comportamiento social. Las redes de contactos y grupos de pertenencia también influyen en su desarrollo (White 2000:64).

El 72\% de adolescentes y jóvenes de los cinco municipios participantes en el estudio considera que la familia es de suma importancia en la formación de valores, poniendo en segundo lugar la escuela (17\%). En menor proporción está la religión y la comunidad, sin diferencias significativas entre los géneros. Esta proporción es similar a la encontrada en el Informe de Desarrollo Humano 2011 (PNUD, 2011) en el cual más del $70 \%$ de jóvenes considera la familia como una de sus principales fuentes de apoyo para su desarrollo como hombre o mujer. El gobierno, la iglesia y otras instituciones prácticamente no tienen presencia en el referente juvenil.

\section{Preponderancia materna en hogares desintegrados}

El estudio identificó muchas familias desintegradas. Solo el $41 \%$ de adolescentes y jóvenes reconoció como núcleo familiar a ambos progenitores. Esto significa que el 59\% vivía en familias desintegradas. De estos últimos, el 34\% vivía únicamente con su madre; el $3 \%$, con su padre, y un $18 \%$ con otras personas no incluyendo quienes ya tienen su propia pareja (4\%).

El núcleo familiar es similar en todos los municipios con excepción de la Desembocadura de la Cruz de Río Grande donde el $33 \%$ vive con ambos progenitores y el $43 \%$ con su madre nada más. Esto indica que las madres asumen toda la carga para la subsistencia de la familia y es alto el abandono de la figura paterna. Cabe mencionar que para uno de cada cuatro adolescentes y jóvenes de Bluefields

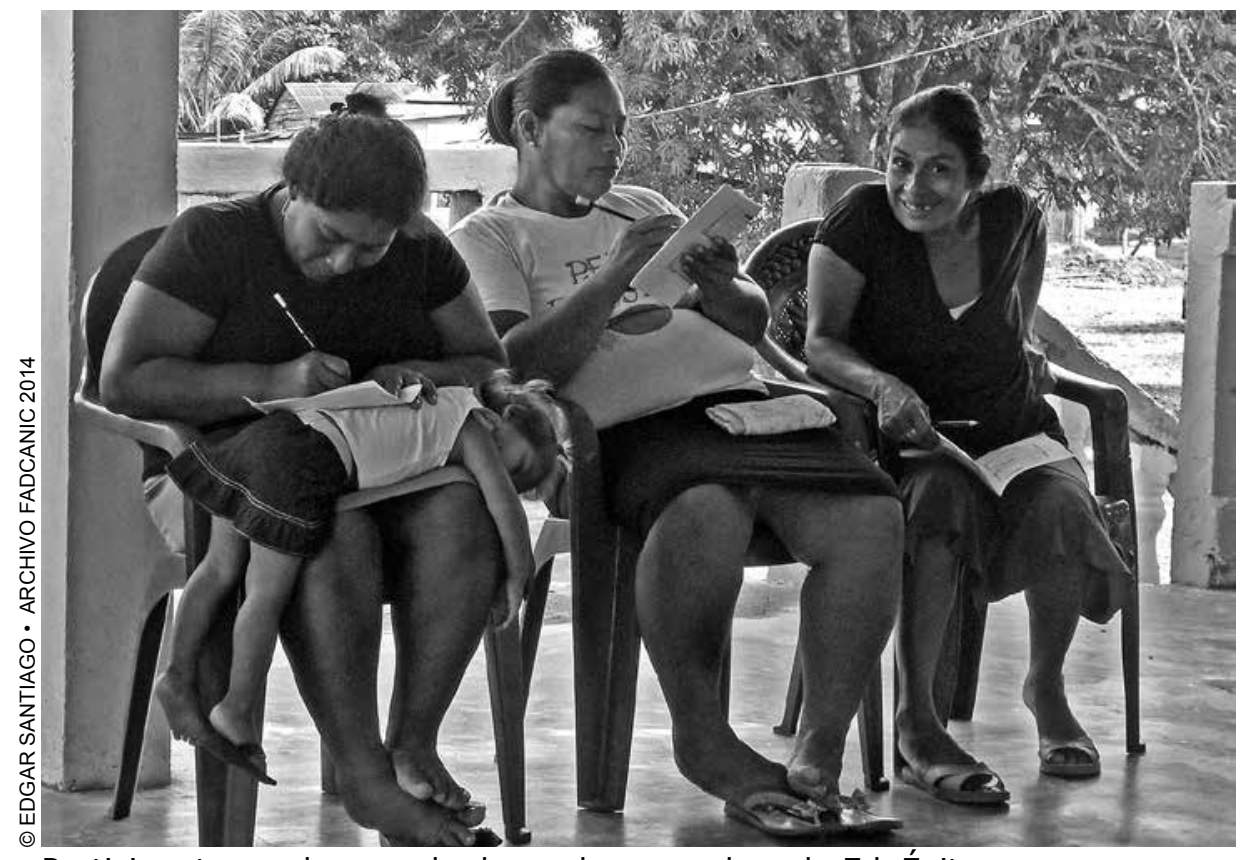

Participantes en la escuela de madres y padres de EduÉxito.

Sin embargo hay conciencia de que tal imagen de la familia no se ajusta plenamente a la realidad (Salles y Tuirán, 1996), por dos tipos de razones que analíticamente deben ser distinguidas. Una es la permanente tensión entre la dependencia y obediencia, que deben tener las personas jóvenes en el seno de la familia, y la emancipación como parte de la cualidad más importante del proyecto de vida de la juventud. Otra razón está ligada a las desigualdades presentadas en los procesos de socialización, formación de valores, modelos de conductas y transmisión de activos de las familias a sus integrantes, ya que estos procesos estarán en dependencia de la estratificación de clases; así, familias ricas transmitirán abundantes activos a sus generaciones, pero lo contrario ocurrirá con familias más pobres, quedando solo la trasmisión intergeneracional de la pobreza. 
y Corn Island, su núcleo familiar lo componen otras personas. Esto podría ser producto de las migraciones o por encontrarse dichos jóvenes en situación de abandono $u$ orfandad, lo cual es un factor de vulnerabilidad que puede repercutir en su desarrollo.

\section{Afectividad y violencia en la familia}

Según el PNUD "el hogar no es sólo el medio donde se organiza la sobrevivencia sino también el ámbito de las conexiones afectivas fundamentales, las relaciones sexuales, la reproducción física y social; es el lugar donde se ejercen las responsabilidades y se experimentan las consecuencias de la vida en común". En el estudio se valoró las relaciones de adolescentes y jóvenes con ambos progenitores, encontrando evidencia que no todas las familias conviven armónicamente y que, en algunos casos, sus relaciones pueden ser insostenibles. El $48 \%$ afirmó que su relación con el padre era de regular a ninguna incluyendo un $11 \%$ que tenía el padre ausente ${ }^{8}$.
Con las madres parece existir una mejor comunicación, lo que apunta a un importante vínculo de confianza y afecto con éstas. En esta población solo el $11 \%$ calificó de regular a difícil o no tener ninguna relación con su mamá. Otro $6 \%$ indicó que no vivía con su madre o que ésta había fallecido. (Tabla 4.)

Al hacer el cruce en la relación con ambos progenitores, se encontró incluso que entre todos y todas las jóvenes que manifestaron tener relación difícil, muy difícil y no relación con su padre, el 74\% manifestó tienen una relación muy buena y buena con la madre. El 26\% de adolescentes y jóvenes restante se considera una población particularmente vulnerable, dado que además de que tenían una relación de muy difícil a ninguna con el padre, también tenían una relación de muy difícil a ninguna con la madre.

A esto se suma que el $31 \%$ del total de la muestra había recibido violencia física (golpes) por parte de progenitores y otros adultos con quienes vivía. E1 26\% había presenciado actos de violencia entre su familia, sobre todo en Pearl Lagoon y Kukra Hill.

\section{Tabla 4. Relaciones familiares de adolescentes y jóvenes de cinco municipios de la RACS (en porcentajes)}

\begin{tabular}{|c|c|c|c|c|c|c|}
\hline Calidad de la Relación & Bluefields & Corn Island & $\begin{array}{l}\text { Desembocadura } \\
\text { de Rio Grande }\end{array}$ & Kukra Hill & $\begin{array}{l}\text { Laguna de } \\
\text { Perlas }\end{array}$ & Total \\
\hline \multicolumn{7}{|l|}{ Relación con el padre } \\
\hline Buena a muy buena & 47 & 59 & 47 & 57 & 51 & 52 \\
\hline Regular a muy difícil & 12 & 28 & 17 & 17 & 27 & 20 \\
\hline Ninguna/No me relaciono & 18 & 6 & 27 & 20 & 14 & 17 \\
\hline Padre ausente (fallecido o desconocido) & 23 & 7 & 9 & 6 & 8 & 11 \\
\hline \multicolumn{7}{|l|}{ Relación con la madre } \\
\hline Buena a muy buena & 75 & 90 & 82 & 81 & 86 & 83 \\
\hline Regular a muy difícil & 16 & 5 & 11 & 10 & 8 & 10 \\
\hline Ninguna/No me relaciono & 1 & 1 & 5 & 0 & 0 & 1 \\
\hline Madre ausente (fallecida o no vivo con ella) & 8 & 4 & 2 & 9 & 6 & 6 \\
\hline \multicolumn{7}{|l|}{ Violencia intrafamiliar } \\
\hline $\begin{array}{l}\text { Ha recibido golpes } \\
\text { (algunas veces, frecuentemente o siempre) }\end{array}$ & 12 & 27 & 21 & 30 & 71 & 31 \\
\hline $\begin{array}{l}\text { Ha presenciado actos de violencia } \\
\text { entre miembros de la familia }\end{array}$ & 13 & 26 & 17 & 35 & 46 & 26 \\
\hline
\end{tabular}

Fuente: Elaboración propia basado en datos de FADCANIC 2013.

8 El informe de las Naciones Unidas “El Desarrollo Humano en Nicaragua 2000”, en su capítulo 7 referido a la familia, aproxima el concepto de hogar al de familia.

9 Se refiere a padre desconocido o fallecido. 


\section{Impacto de las migraciones}

Son pocos jóvenes de estos municipios quienes han estado fuera del país: $16 \%$ de hombres y $13 \%$ de mujeres. No se detalla en el estudio las causas de su salida, su fecha de regreso o en qué países han estado, variables muy importantes para analizar la transculturización de la juventud y los procesos de adaptación que han tenido que pasar debido a estos cambios de domicilio que también influyen en el grado de vulnerabilidad.

En el estudio, el 38\% de los adolescentes y jóvenes varones y el $31 \%$ de las mujeres tenían familiares que enviaban remesas desde el exterior. La mayoría de jóvenes que tiene familiares en el exterior que les envían remesas se localiza en los municipios de Kukra Hill y Laguna de Perlas (40\% cada uno), seguido de Corn Island (37\%). En la Desembocadura de la Cruz de Río Grande es de donde menos emigran.

No se determina en el estudio si los familiares que estaban en el exterior eran padres y madres u otro pariente. Sin embargo, en la medida en que la madre es la principal referente en la vida de adolescentes y jóvenes en la región, la emigración de ésta afecta mucho a sus hijos e hijas. Según un estudio (Cranshaw y Morales, 1998), las mujeres que emigran, al volver al país recuperan la tranquilidad. Pero, en el caso de infantes, adolescentes y jóvenes, la tristeza y el no contar con una confidente y una guía suele tener un impacto durante y después de la migración, lo cual afecta su sano desarrollo, sobre todo cuando no existe una adecuada comunicación. En este sentido sería muy importante conocer cuántos de estos adolescentes y jóvenes tienen a su madre fuera del país, ya que éstos tendrían mayor vulnerabilidad y deberían ser incluidos en programas específicos que les permitan continuar con su desarrollo integral.

\section{Economía familiar}

Es importante conocer cómo es el nivel de empleo e ingreso de las familias de adolescentes y jóvenes participantes en el estudio. Da una idea de los activos con que cuentan para su sobrevivencia sobre todo si no tienen empleo o si éste es tan precario que no llena sus necesidades básicas.

Las familias en los cinco municipios del estudio están compuestas en promedio por seis miembros, siendo el mínimo cinco integrantes para el caso de las familias de Bluefields y Kukra Hill, y siete el máximo para las familias del municipio de Desembocadura de la Cruz de Río Grande. En promedio, el 53\% del total de adultos tiene algún tipo de ingresos fijos. Por municipio se observa que
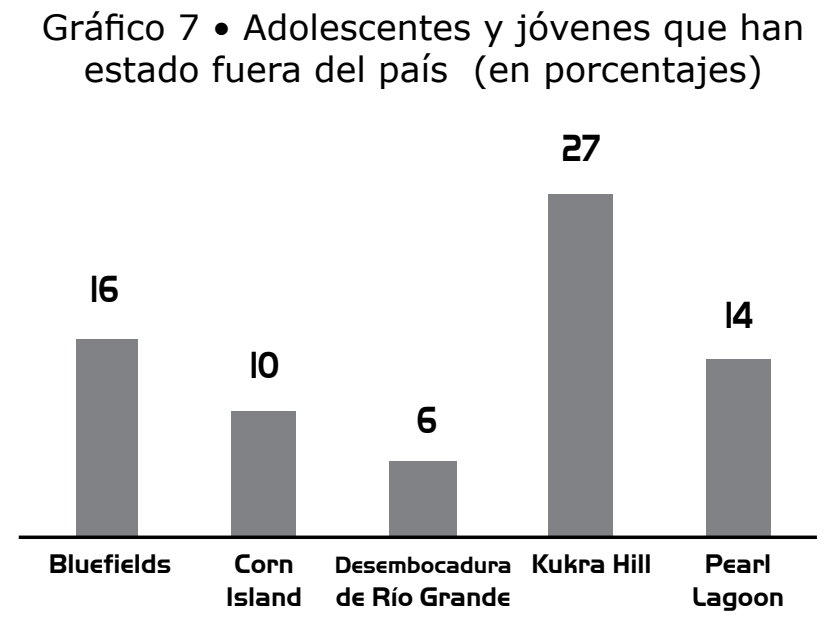

Fuente: Elaboración propia basado en datos de FADCANIC 2013.
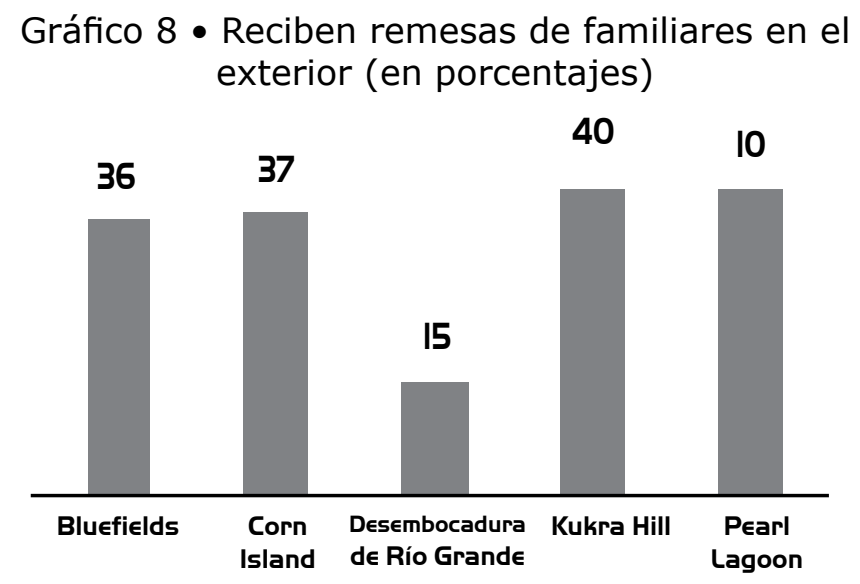

Fuente: Elaboración propia basado en datos de FADCANIC 2013.

\section{¿úmero de habitantes por familia Nivel de empleo por familia}

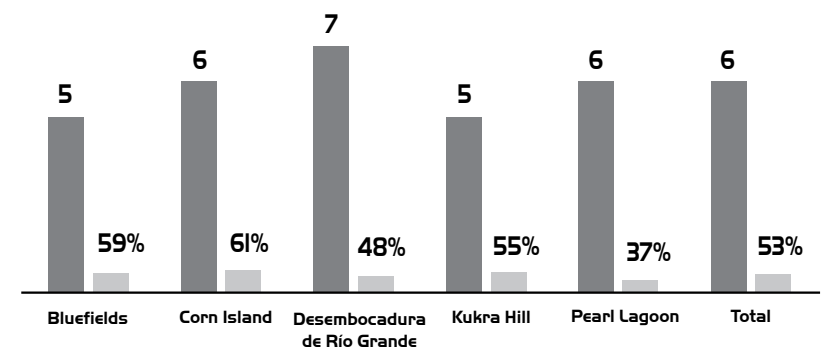

Fuente: Elaboración propia basado en datos de FADCANIC 2013. 
en Bluefields, Corn Island y Kukra Hill, más del 50\% de los adultos tiene un ingreso fijo; en cambio, en los municipios de Pearl Lagoon y en la Desembocadura de la Cruz de Río Grande, menos del 50\% posee un ingreso fijo. (Gráfico 8.)

Más de la mitad de adolescentes y jóvenes participantes en el estudio dependía de sus padres (51\%). El 27\% se auto sostenía. Se observa diferencias de género, pues más varones dependían de sus padres. La mayoría de quienes afirmaban depender de sí mismos fueron varones y el $90 \%$ de quienes dependían de su cónyuge fueron mujeres. (Tabla 5.)

Al relacionar el ingreso mensual de las familias con el gasto mensual, tenemos que el $85.8 \%$ de las familias subsisten con un ingreso igual o menor de los $\mathrm{C} \$ 5,000.00$ córdobas al mes. (Tabla 6.) Este valor representaba la mitad de la canasta básica ${ }^{10}$ en el momento del estudio. Esto significa que la mayoría de las familias no puede satisfacer sus necesidades básicas catalogándose por tanto s como hogares en pobreza.

Esta adición de "factores de desventaja" aumenta la probabilidad de que: (1) las funciones familiares básicas no puedan ser cumplidas y (2) las nuevas generaciones de estos hogares se socialicen en forma claramente desmejoradas, lo que va en franco perjuicio de estos y estas jóvenes. Esto significa que las funciones de ofrecer un espacio cotidiano cómodo y un ancla de seguridad ontológica ${ }^{11}$ no se cumplen forzosamente en las familias reales. Es por esto que es necesario desarrollar políticas y programas para incidir en el mejoramiento de las relaciones familiares y del ingreso de las familias.

\section{Tabla 5. Distribución de las personas de quienes dependen adolescentes y jóvenes de cinco municipios de la RACS (en porcentajes)}

\begin{tabular}{lccccccccccccc}
\hline $\begin{array}{c}\text { De quién } \\
\text { depende }\end{array}$ & \multicolumn{2}{c}{ Bluefields } & \multicolumn{2}{c}{ Corn Island } & \multicolumn{2}{c}{$\begin{array}{c}\text { Desembocadura } \\
\text { de Rio Grande }\end{array}$} & Kukra Hill & \multicolumn{2}{c}{ Laguna de Perlas } & Total \\
económicamente & Mujeres & Hombres & Mujeres & Hombres & Mujeres & Hombres & Mujeres & Hombres & Mujeres & Hombres & Mujeres & Hombres \\
\hline De sí & 34 & 44 & 10 & 15 & 34 & 27 & 17 & 38 & 20 & 30 & 23 & 31 \\
De sus progenitores & 44 & 44 & 51 & 68 & 49 & 51 & 42 & 51 & 50 & 61 & 47 & 55 \\
De sus parejas & 16 & 0 & 23 & 5 & 9 & 6 & 25 & 0 & 13 & 0 & 18 & 2 \\
De otro pariente & 6 & 10 & 8 & 10 & 9 & 16 & 16 & 11 & 7 & 9 & 9 & 11 \\
De otra persona & 0 & 3 & 7 & 3 & 0 & 0 & 0 & 0 & 10 & 0 & 3 & 1 \\
\hline
\end{tabular}

Fuente: Elaboración propia basado en datos de FADCANIC 2013.

Tabla 6. Gasto familiar mensual vs. Ingreso familiar mensual de adolescentes y jóvenes de cinco municipios de la RACS (en porcentajes)

\begin{tabular}{|c|c|c|c|c|c|c|}
\hline \multirow{2}{*}{$\begin{array}{c}\text { Gasto mensual aproximado } \\
\text { de la familia }\end{array}$} & \multicolumn{6}{|c|}{ Ingreso mensual de la familia } \\
\hline & $C \$ 2000$ & $C \$ 3000$ & $c \$ 4000$ & $\mathrm{C} \$ 5000$ & $\begin{array}{l}\text { Más de C\$ } \\
\quad 5000\end{array}$ & TOTAL \\
\hline Menos de C\$2000 & 11 & 8 & 4 & 1.4 & 4 & 28.4 \\
\hline Entre C\$2000 y C\$ 4000 & 3 & 10 & 11 & 6 & 10 & 40 \\
\hline Entre $C \$ 4000$ y $C \$ 5000$ & 0.4 & 2 & 3 & 4 & 8 & 17.4 \\
\hline Más de C\$ 5000 & 0 & 0 & 1.4 & 0.8 & 12 & 14.2 \\
\hline TOTAL & 14.4 & 20 & 19.4 & 12.2 & 34 & 100 \\
\hline
\end{tabular}

Fuente: Elaboración propia basado en datos de FADCANIC 2013.

10 Según el Banco Central de Nicaragua en su índice de precios al consumidor, la canasta básica andaba por el valor de C\$ 10,335.10 a julio del 2012.

11 Seguridad ontológica en cuanto al grado de seguridad que tiene la persona en situaciones de la vida cotidiana, lo que tiende a generar un sentimiento de confianza en las otras personas. 


\section{DIMENSIÓN SOCIOECONÓMICA}

El enfoque de la agencia ${ }^{12}$ sostiene que aún entre los pobres existen capacidades que pueden ser movilizadas para conseguir un mayor nivel de bienestar. No se trata de asignar a los pobres la responsabilidad de superar su propia pobreza, más bien se trata de activar su responsabilidad y autonomía para generar procesos donde no dependan de decisiones ajenas sino que actúen como sujetos capaces de gestionar los procesos que los involucran y hacer que los estados y la sociedad asuman también sus responsabilidades. (IDH, 2011)

\section{Acceso a educación}

Para lograr que las juventudes movilicen estas capacidades de agencia se hace necesario que tengan una mejor educación. La educación es una dimensión esencial en el desarrollo de las personas, porque amplía el abanico de opciones y oportunidades de que disponen para elegir la vida que valoran y anhelan. Pero la realidad en Nicaragua es que cuatro de cada diez adolescentes está fuera del sistema educativo (IDH, 2011).
En estos cinco municipios el estudio encontró $60 \%$ de adolescentes y jóvenes que no estaban estudiando. O sea, solo el $40 \%$ de esta población de quince a veinticuatro años estaba estudiando, incluyendo un 6\% integrado al Programa Educación para el Éxito de FADCANIC y USAID.

El cien por ciento de los y las entrevistadas debería tener la primaria completa y todos los que están entre 20 y 24 años (que representan el $42 \%$ de la muestra) deberían haber terminado la secundaria.

Igualmente preocupante es el hecho de que habían completado la primaria solo el $16 \%$ de adolescentes y jóvenes, cuando de acuerdo a la edad, el 100\% debería haber culminado sus estudios de primaria. En la encuesta todavía se encuentra otro $14 \%$ que sigue en la primaria o ha dejado de estudiar sin completarla.

Solamente adolescentes que tenían de quince a dieciséis años al momento del estudio debían tener secundaria incompleta. En el estudio, la población en este rango de edad correspondía al $22 \%$ de la muestra. Sin embargo, $70 \%$ del total de adolescentes y jóvenes tampoco había logrado

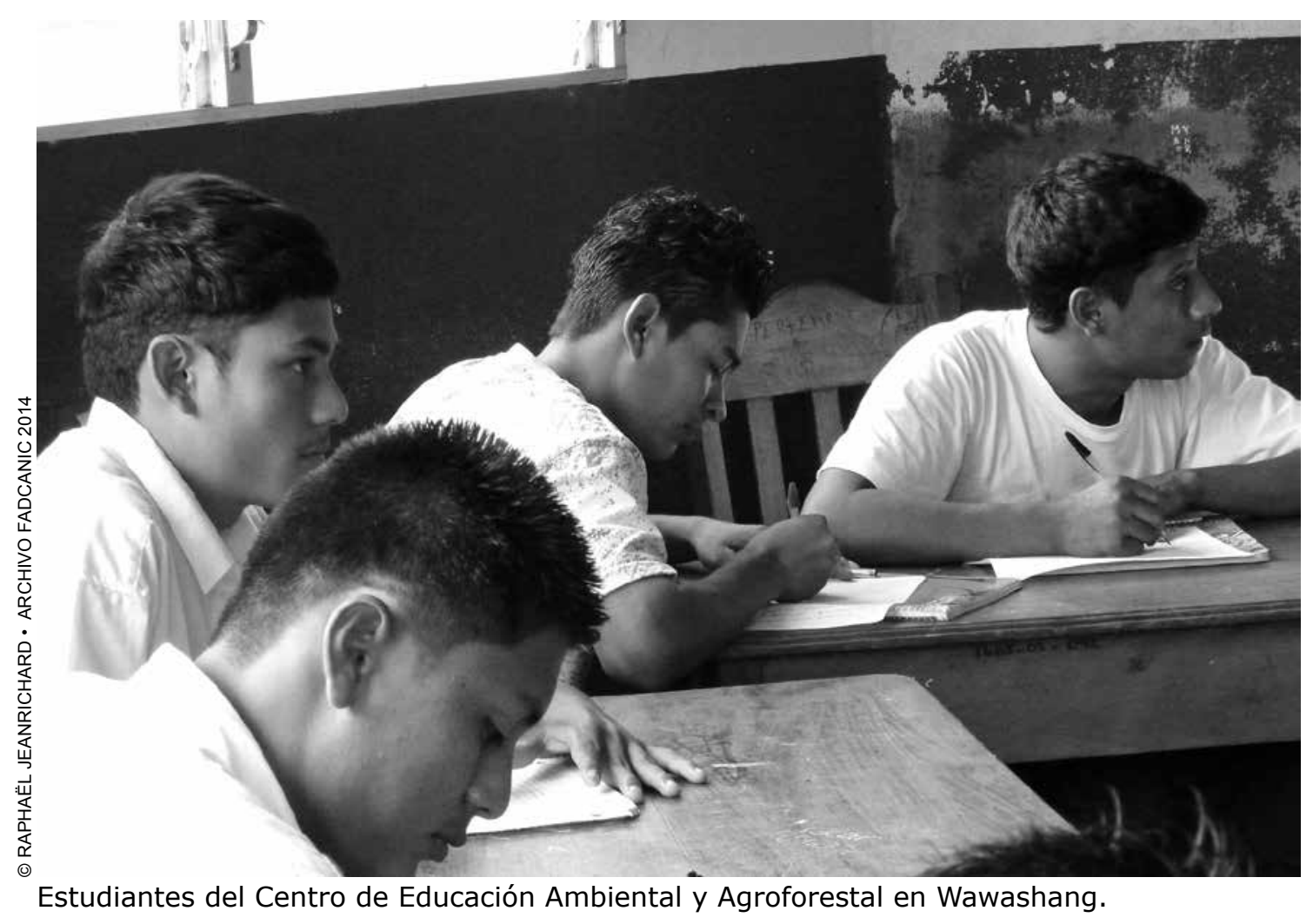

12 Amartya Sen define agencia como "lo que una persona es libre de hacer y alcanzar en la búsqueda de la realización de las metas o los valores que esa persona considere como importantes". 


\section{Tabla 7 - Nivel de escolaridad alcanzada por adolescentes y jóvenes de cinco municipios de la RACS (en porcentajes)}

\begin{tabular}{|c|c|c|c|c|c|c|c|c|c|c|c|c|c|}
\hline \multirow{2}{*}{$\begin{array}{c}\text { Nivel } \\
\text { educativo } \\
\text { alcanzado }\end{array}$} & \multicolumn{2}{|c|}{ Bluefields } & \multicolumn{2}{|c|}{ Corn Island } & \multicolumn{2}{|c|}{$\begin{array}{l}\text { Desembocadura } \\
\text { de Río Grande }\end{array}$} & \multicolumn{2}{|c|}{ Kukra Hill } & \multicolumn{2}{|c|}{$\begin{array}{l}\text { Laguna de } \\
\text { Perlas }\end{array}$} & \multirow[b]{2}{*}{ Mujeres } & \multirow{2}{*}{$\begin{array}{l}\text { Total } \\
\text { Hombres }\end{array}$} & \multirow[b]{2}{*}{$\begin{array}{c}\text { Ambos } \\
\text { Sexos }\end{array}$} \\
\hline & Mujeres & Hombres & Mujeres & Hombres & Mujeres & Hombres & Mujeres & Hombres & Mujeres & Hombres & & & \\
\hline $\begin{array}{l}\text { Primaria } \\
\text { completa }\end{array}$ & 27 & 33 & 9 & 3 & 17 & 16 & 17 & 17 & 3 & 3 & 16 & 15 & 16 \\
\hline $\begin{array}{l}\text { Primaria } \\
\text { incompleta }\end{array}$ & 15 & 16 & 16 & 15 & 26 & 20 & 6 & 13 & 3 & 10 & 14 & 14 & 14 \\
\hline $\begin{array}{l}\text { Secundaria } \\
\text { completa }\end{array}$ & 22 & 17 & 33 & 25 & 11 & 12 & 17 & 12 & 22 & 10 & 23 & 17 & 20 \\
\hline $\begin{array}{l}\text { Secundaria } \\
\text { incompleta }\end{array}$ & 19 & 27 & 39 & 53 & 34 & 41 & 56 & 44 & 57 & 53 & 37 & 43 & 40 \\
\hline $\begin{array}{l}\text { Técnico } \\
\text { completo }\end{array}$ & 6 & 3 & 3 & 0 & 3 & 0 & 0 & 0 & 0 & 0 & 3 & 1 & 2 \\
\hline $\begin{array}{l}\text { Técnico } \\
\text { incompleto }\end{array}$ & 3 & 2 & 0 & 0 & 0 & 0 & 0 & 0 & 0 & 1 & 1 & 1 & 1 \\
\hline $\begin{array}{l}\text { Obrero } \\
\text { Calificado }\end{array}$ & 9 & 3 & 0 & 3 & 6 & 4 & 6 & 4 & 1 & 0 & 4 & 3 & 3 \\
\hline
\end{tabular}

Fuente: Elaboración propia basado en datos de FADCANIC 2013.

completar la secundaria. De tal manera que se puede decir que el $47.5 \%$ estaba en rezago escolar. Solo el $20 \%$ afirmó haber concluido la secundaria, y únicamente el $5 \%$ tenía estudios técnicos o era obrero calificado.

Estos datos reflejan que, en estos municipios, la juventud no tiene acceso pleno a la educación secundaria y mucho menos a una educación técnica o universitaria, que les brinde mayores y mejores oportunidades de empleo.

En general, la escolaridad promedio estimada para el total de jóvenes en la encuesta está entre el sexto y el séptimo grado. Significa que están con un rezago de al menos cinco años para culminar la secundaria, nivel que según la Comisión Económica para América Latina y el Caribe (CEPAL) es considerado el umbral necesario para estar fuera de la pobreza.

\section{Educación y género}

En los niveles de primaria, las diferencias de género no son significativas, sin embargo se observa diferencias de género para alcanzar la secundaria completa, siendo las mujeres las que más alcanzan este nivel (23\%), quedándose los hombres, en su mayoría, en secundaria incompleta (43\%). Solamente en los municipios de Kukra Hill y
Desembocadura, más hombres alcanzan la secundaria. En Kukra Hill, esta diferencia es del 5\%; en Desembocadura es solo de $1 \%$. (Tabla 7. )

En general, también hay más hombres que mujeres fuera del sistema educativo a excepción de Pearl Lagoon y Corn Island. En Corn Island, 80\% de jóvenes varones están fuera de sistema contra $82 \%$ de mujeres. En Pearl Lagoon, la brecha es significativamente mayor, siendo $47 \%$ de varones que no están estudiando, contra $67 \%$ de mujeres.

En la desagregación por municipios, Desembocadura de la Cruz de Río Grande y Corn Island son los municipios con la mayor cantidad de jóvenes que no están estudiando. En Corn Island, un 30\% culminó la secundaria pero no ha continuado sus estudios a pesar de que existen allí extensiones universitarias y técnicas. En la Desembocadura de la Cruz de Río Grande, sólo el 12\% logró culminar la secundaria. En este municipio, la juventud no dispone de ningún establecimiento de educación universitaria o técnica.

\section{Estudio versus ocio}

La mayoría de jóvenes y adolescentes $(91 \%)$ considera que tendrá un mejor futuro laboral si se prepara estudiando. ${ }^{13}$ 
Esto incluye un $88 \%$ de jóvenes que no estaban estudiando; indica que necesitan oportunidades y facilidades reales para reinsertarse en sus estudios y poder optar a un trabajo. Estas podrían ser la posibilidad de poder combinar el estudio con el trabajo ${ }^{14}$, optar a becas ${ }^{15} \mathrm{y}$ tener el apoyo de la familia ${ }^{16}$.

El hecho es que $32 \%$ reportó que no estudiaba porque no tenía recursos; mientras que $18 \%$ trabajaba, por lo cual no podía estudiar. En el caso de adolescentes y jóvenes mujeres, una de cada cuatro dijo que no estudia por falta de recursos y una de cada cinco, porque no tenía tiempo. En general, esta variable es mayor en las mujeres debido a los roles de género que le asignan el de cuidadora de otros miembros de la familia o bien de sus propios hijos.

Muchos estudiantes de secundaria abandonan sus estudios, no sólo por problemas económicos o circunstancias de vida difícil, sino por una oferta educativa que no es pertinente a sus necesidades y expectativas. En este sentido, es muy importante destacar que uno de cada cuatro adolescentes y jóvenes varones no estudiaba porque no quería.

Además, en el estudio, uno de cada tres adolescentes y jóvenes indicó no desear hacer nada $(5 \%)$ o no contesta la pregunta $(25 \%)$ sobre lo que quiere para el futuro, lo cual es una proporción considerable. Por tal razón, para futuras intervenciones es necesaria la delimitación de esta población, porque se necesitaría mucha motivación y conocer sus condiciones económicas y psicosociales, para reintegrar estos jóvenes a procesos educativos y productivos. También se debe subrayar que, independiente de cual sean los motivos, uno de cada cinco adolescentes y jóvenes se encuentran en alto grado de exclusión social, porque no trabajan ni estudian.
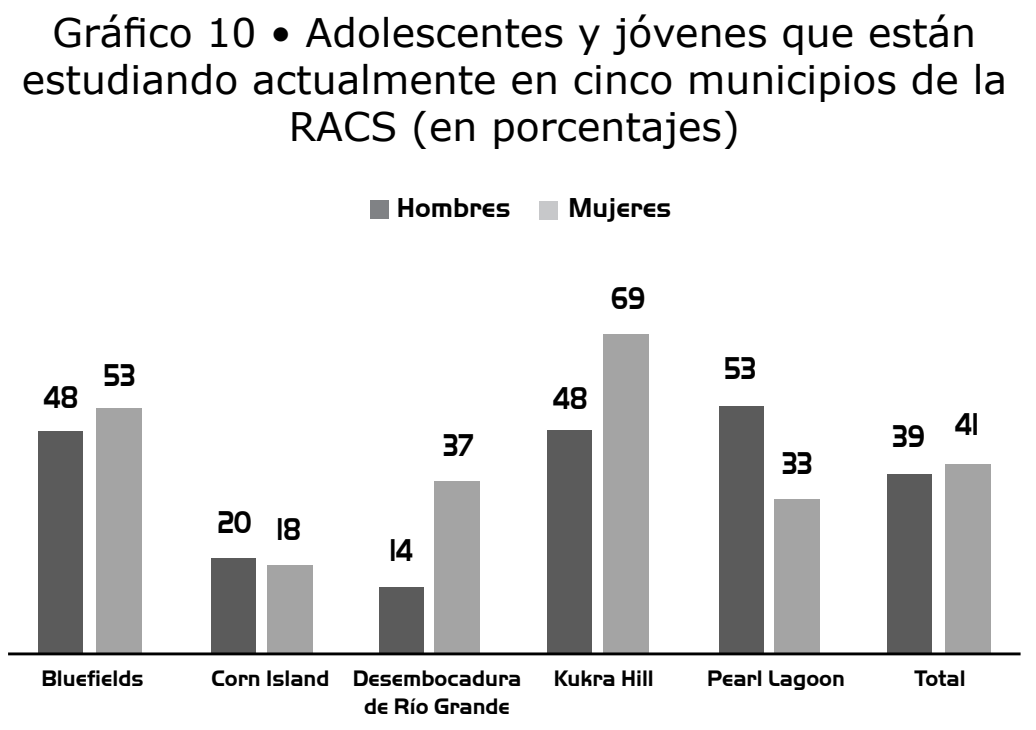

Fuente: Elaboración propia basado en datos de FADCANIC 2013.

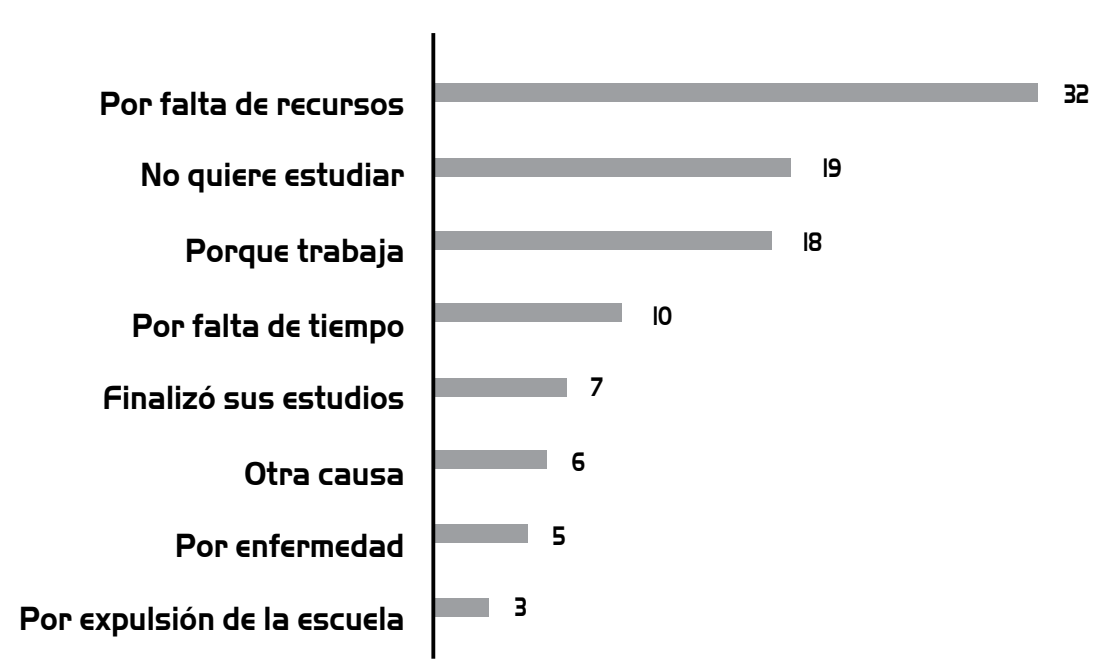

Fuente: Elaboración propia basada en datos de FADCANIC 2013.

13 Solo la Desembocadura de la Cruz de Río Grande reportó menor cantidad de personas (77\%) que apoyaron esta opinión, siendo las mujeres quienes más están en desacuerdo (26\%).

14 El 31\% de la encuesta dice que lo que gustaría hacer para poder seguir estudiando es trabajar y estudiar.

15 El 22\% dice que le gustaría conseguir una beca para poder seguir estudiando.

16 El $8 \%$ dice que lo que necesita para seguir estudiando es tener el apoyo de la familia. 


\section{Tabla 8 • Adolescentes y jóvenes que no trabajan y no estudian en cinco municipios de la RACS (en porcentajes)}

\begin{tabular}{cccccccccccccc}
\hline $\begin{array}{c}\text { Rango } \\
\text { de Edad }\end{array}$ & \multicolumn{2}{c}{ Bluefields } & \multicolumn{2}{c}{ Corn Island } & \multicolumn{2}{c}{$\begin{array}{c}\text { Desembocadura } \\
\text { de Rio Grande }\end{array}$} & Kukra Hill & \multicolumn{2}{c}{$\begin{array}{c}\text { Laguna de } \\
\text { Perlas }\end{array}$} & \multicolumn{2}{c}{ Total } \\
& Mujeres & Hombres & Mujeres & Hombres & Mujeres & Hombres & Mujeres & Hombres & Mujeres & Hombres & Mujeres & Hombres & $\begin{array}{c}\text { Ambos } \\
\text { Sexos }\end{array}$ \\
\hline $15-19$ & 16 & 16 & 26 & 5 & 32 & 26 & 13 & 11 & 14 & 15 & 20 & 15 & 17 \\
$20-24$ & 21 & 13 & 25 & 43 & 25 & 20 & 50 & 17 & 13 & 17 & 25 & 21 & 24 \\
Total & 18 & 15 & 25 & 23 & 29 & 23 & 26 & 13 & 14 & 16 & 23 & 17 & 20 \\
\hline
\end{tabular}

Fuente: Elaboración propia basada en datos de FADCANIC 2013.

\section{Educación Técnica}

La mayoría de adolescentes y jóvenes (89\%) manifestó, con diferencias mínimas entre los sexos, que le gustaría aprender un oficio mientras estudia. Esto representa un desafío para el sector educativo puesto que supone la capacidad de vincular la secundaria a la educación técnica en carreras que brinden la oportunidad de formación para el empleo de acuerdo a las necesidades de los municipios.

Sin embargo, para la juventud que no tiene un diploma de secundaria, las únicas opciones disponibles para la educación técnica en estos cinco municipios son el Instituto Politécnico Cristóbal Colón de INATEC en Bluefields, la Escuela de Turismo de INATEC en Corn Island, y el Centro de Educación Ambiental y Agroforestal de FADCANIC en Wawashang, municipio de Pearl Lagoon.

En la encuesta, la juventud indica áreas técnicas a priorizar: diseño de ropa y mecánica en todos los municipios, cocina en 4 de los cinco, Agroforestería y turismo en 3 y agricultura, artesanía, carpintería, construcción, electricidad, electrónica, y navegación en al menos municipios.

Existen diferencias de género en la preferencia de áreas. Los hombres prefieren mecánica, agroforestería y agricultura, mientras las mujeres, diseño de ropa, cocina y turismo. Estas diferencias de género promueven la continuidad de los roles tradicionales que también constituyen un desafío de la educación técnica.

Tabla 9 • Áreas técnicas más demandadas por adolescentes y jóvenes en cinco municipios de la RACS

\begin{tabular}{ccccc}
\hline Bluefields & Corn Island & Desembocadura & Kukra Hill & Pearl Lagoon \\
\hline Diseño de Ropa & Diseño de Ropa & Mecánica & Agricultura & Mecánica \\
Electricidad & Navegación & Agroforestería & Mecánica & Agroforestería \\
Mecánica & Cocina & Agricultura & Agroforestería & Turismo \\
Hotelería & Turismo & Artesanías & Construcción & Cocina \\
Navegación & Mecánica & Diseño de Ropa & Diseño de ropa & Diseño de Ropa \\
Electrónica & Electrónica & Carpintería & Cocina & Carpintería \\
Artesanía & Electricidad & Cocina & Turismo & Construcción \\
\hline
\end{tabular}

Las áreas sombreadas refieren a que como mínimo $15 \%$ de quienes fueron encuestados en ese municipio afirmaron que les gustaría estudiar esa área técnica. En cada municipio las áreas están listadas de mayor a menor preferencia. 


\section{Tabla $10 \bullet$ Oportunidades laborales identificadas por actores claves en cinco municipios de la RACS}

\begin{tabular}{|c|c|c|c|}
\hline Jóvenes & Líderes & Mixtos* & Progenitores \\
\hline Pesca Artesanal & Pesca Artesanal & Pesca Artesanal & Pesca Artesanal \\
\hline Diseño de Ropa & Diseño de Ropa & Diseño de Ropa & Diseño de Ropa \\
\hline Reforestación & Reforestación & Reforestación & \\
\hline Artesanía & Artesanía & & Artesanía \\
\hline Turismo & Turismo & & Turismo \\
\hline Agricultura & & Agricultura & Agricultura \\
\hline \multirow[t]{2}{*}{ Mecánica } & & Mecánica & Mecánica \\
\hline & Ebanistería & Ebanistería & Ebanistería \\
\hline Construcción & Construcción & & \\
\hline Navegación & Navegación & & \\
\hline Hotelería & & & Hotelería \\
\hline \multirow[t]{10}{*}{ Electricidad } & & Electricidad & \\
\hline & Explotación pesquera & & Explotación pesquera \\
\hline & Explotación de camarones & Explotación de camarones & \\
\hline & Docencia & Docencia & \\
\hline & Procesamiento de alimentos & & \\
\hline & Computación & & \\
\hline & Construcción, albañilería & & \\
\hline & & & Exportación de coco y cacao \\
\hline & & & Carpintería \\
\hline & & & Panadería \\
\hline Cocina & & & \\
\hline
\end{tabular}

* En las comunidades pequeñas se hizo un solo grupo focal mixto, con participantes líderes, docentes, padres y madres de familia.

Las áreas para la formación técnica que fueron identificadas en los grupos focales con adultos, adolescentes y jóvenes llegan a variar entre sí, aunque de forma general las preferencias de la juventud se ven reflejadas también en las de las personas adultas. Las oportunidades laborales que los adultos ven en sus territorios, sin embargo, no están necesariamente entre las preferencias de la juventud por lo que debería haber un plan municipal de educación para la empleabilidad de la juventud, que identifique verdaderamente las áreas donde es posible formar para el empleo a las generaciones venideras.

En el caso de la pesca, por ejemplo, la juventud no la propone como prioridad para tecnificarse en esa área.
Incluso, la agricultura es poco mencionada, a pesar que son actividades que se han venido desarrollando y en las cuales, habiendo aprendido de forma empírica, se emplean actualmente una parte significativa de la mano de obra juvenil. (Tabla 10.)

\section{Acceso a empleo}

El acceso al empleo es un factor muy importante para el desarrollo de la juventud en Nicaragua. Según la Encuesta de Medición del Nivel de Vida del 2009, había en ese periodo 553,000 jóvenes entre quince y veintinueve años que no estudiaban ni trabajaban. 
Entre la población de 15 a 24 años, que no trabajaban ni estudiaban la RACS presentaba la segunda proporción más alta de todo el país con una tasa de $32.2 \%$ contra la media nacional de $26 \%$. Este riesgo era muchisimo mayor entre las mujeres jóvenes, siendo que en la RACS, $54.8 \%$ de ellas no estaban trabajando ni estudiando contra $9.1 \%$ de hombres en esta condición.

En los cinco municipios que son objeto del estudio, más de la mitad de jóvenes estaba trabajando (57\%); de éstos, el $64 \%$ son varones y el $49 \%$ mujeres. E1 $51 \%$ de las mujeres encuestadas se encontraban desempleadas, siendo el mayor desempleo entre las mujeres una constante en todos los municipios. La menor brecha entre hombres y mujeres desempleadas se encontró en Corn Island y en Laguna de Perlas. En los otros tres municipios la diferencia de 19 hasta 32 puntos porcentuales, siendo las jóvenes de la Desembocadura de la Cruz de Río Grande las que tienen la mayor brecha de género en términos de empleo. (Gráfico 11.)

De forma general, los trabajos que realizaban adolescentes y jóvenes fueron, en mayor medida: pesca, trabajo doméstico, construcción, agricultura y trabajo por cuenta propia.

En el tipo de trabajo que desempeñaban los hombres destacan, en orden de importancia: pesca, construcción, agricultura y trabajo doméstico.

En cambio, las mujeres, en su mayoría se dedican al trabajo doméstico, trabajo por cuenta propia y a la pesca (Gráfico 13). Los municipios de Bluefields y Kukra Hill son los que tienen más variedad de trabajos para jóvenes varones, mientras en Corn Island sobresale la pesca.

E1 37\% de quienes trabajan expresaron que tenían otra actividad económica que les generaba ingresos; las
Gráfico 12 • Adolescentes y jóvenes que trabajan en cinco municipios de la RACS (en porcentajes)

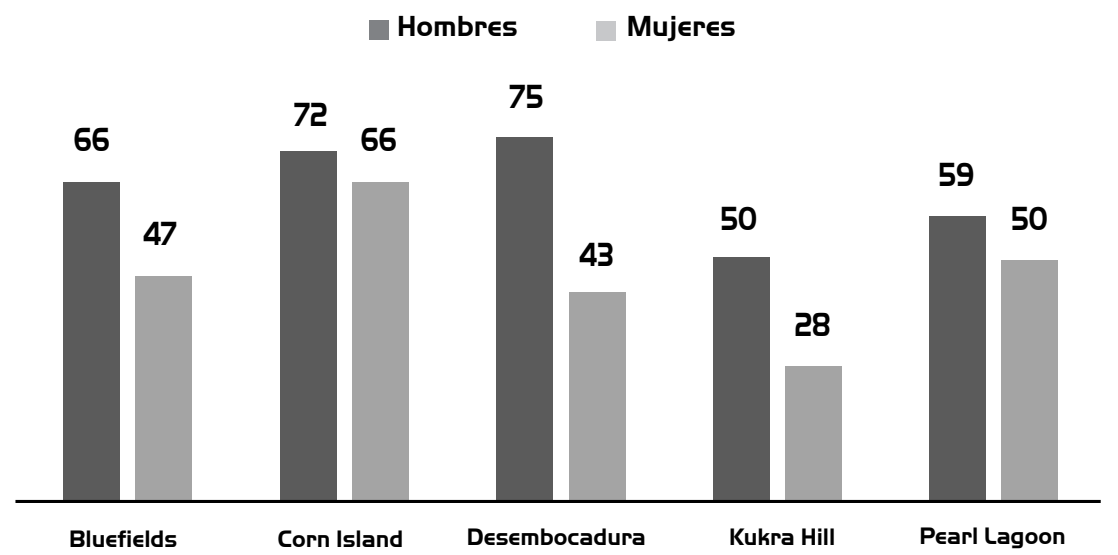

Fuente: Elaboración propia basada en datos de FADCANIC 2013.

Gráfico 13 • Tipos de trabajo que realizan adolescentes y jóvenes en cinco municipios de la RACS (en porcentajes)

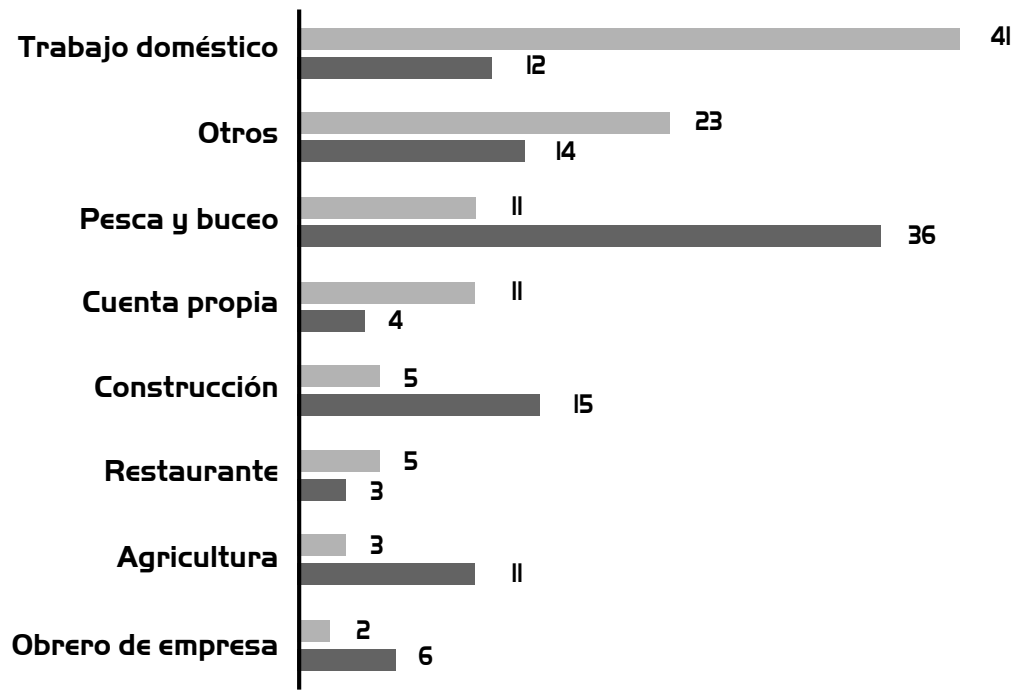

Fuente: Elaboración propia basado en datos de FADCANIC 2013. diferencias de género son mínimas en esta variable. La mayoría de quienes realizan más de una actividad económica se localiza en el municipio de Pearl Lagoon y Corn Island, seguido de Desembocadura de Río Grande. Su primer trabajo es la pesca, el trabajo doméstico o la construcción. 


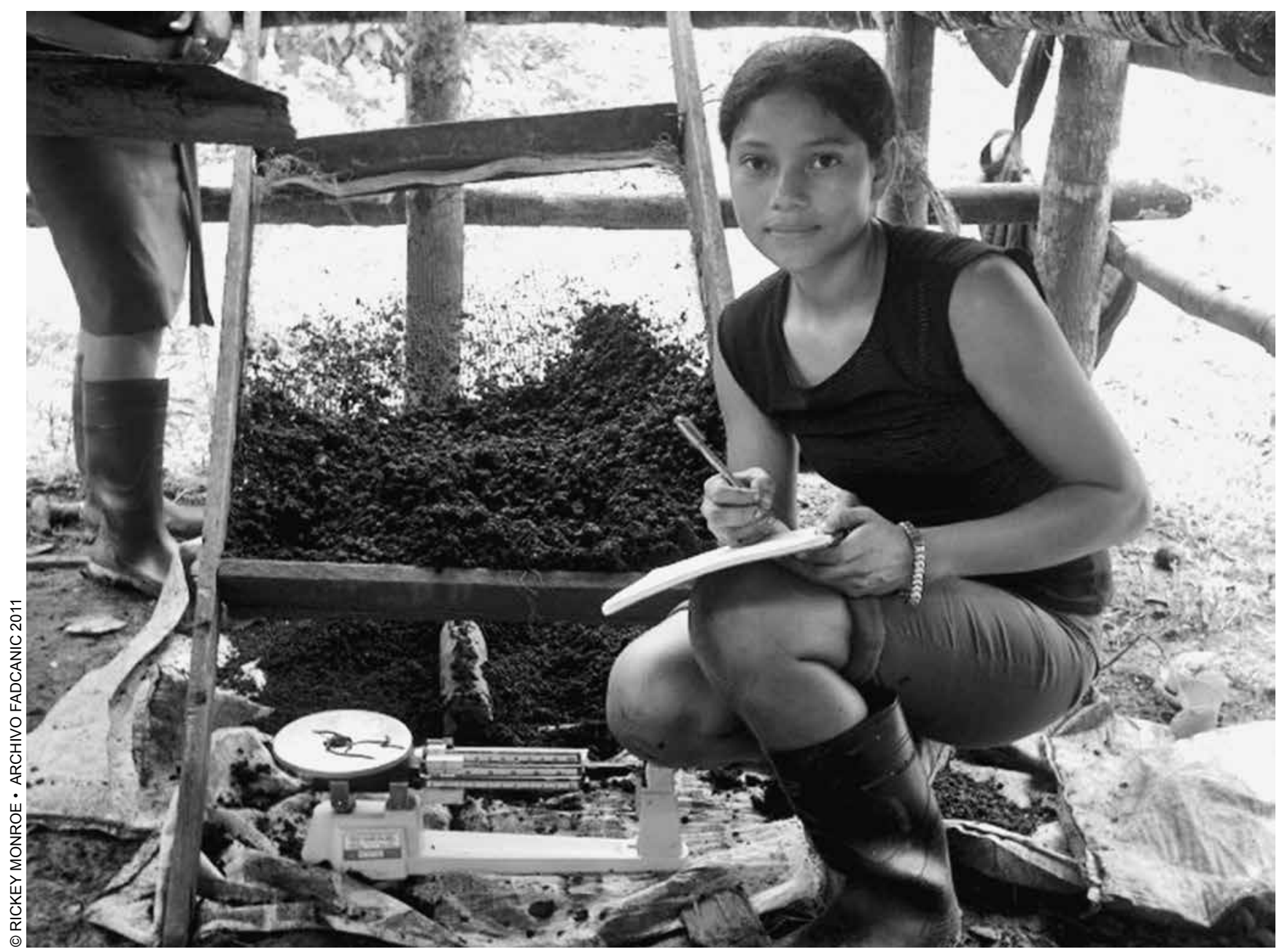

Estudiante del Centro de Educación Ambiental y Agroforestal en Wawashang.

Destaca, también, el hecho que únicamente el $6 \%$ de la población encuestada posee trabajo permanente, siendo ésta, en mayor número, varones y localizados en el municipio de Kukra Hill. De quienes trabajan de forma permanente, la mayoría lo hace como obrero de empresa, trabajo doméstico y pesca.

La mayor parte de los trabajos que realizan caen en la categoría de subempleo. Lo ejecutan sin contrataciones, de manera informal y temporal. En el caso de trabajo doméstico, el estudio no define si es remunerado o no, lo que podría dar mejores luces de la situación de quienes realizan este trabajo.

El 29\% de jóvenes que no trabaja, no lo hace porque está estudiando, $39 \%$ porque no hay trabajo o no encuentra trabajo, $13 \%$ cree no estar preparados y $6 \%$ no posee su cédula de identidad o partida de nacimiento. (Tabla 11.)

Cabe mencionar que los encuestados de todos los municipios comparten las mismas respuestas del porqué no trabajan. En este sentido destaca el caso de Corn Island donde en mayor medida se identifica el problema de la falta de cédula de identidad, también el caso de Kukra Hill donde el 10\% manifestó no trabajar porque no tiene quien cuide de sus hijos o por quehaceres en el hogar. Es importante destacar también que, en el municipio de Kukra Hill, el $61 \%$ no trabaja porque estudia, indicador muy importante que se convertirá en un factor protector si estos y estas jóvenes logran alcanzar los once años de estudio.

De forma general, en los cinco municipios es necesario elaborar estrategias que amplíen las oportunidades para continuar sus estudios y, además, para poder contar con un empleo digno. Esto incluye:

- definir estrategias de educación que permitan a la juventud que trabaja continuar con sus estudios (horarios de clases sabatinos y dominicales, y bachillerato acelerado sin perder la calidad educativa); 
Tabla 11 - Razones por las cuales no trabajan adolescentes y jóvenes de cinco municipios de la RACS (en porcentajes)

\begin{tabular}{|c|c|c|c|c|c|c|}
\hline Razones & Bluefields & Corn Island & $\begin{array}{l}\text { Desembocadura } \\
\text { de Rio Grande }\end{array}$ & $\begin{array}{c}\text { Kukra } \\
\text { Hill }\end{array}$ & $\begin{array}{l}\text { Laguna } \\
\text { de Perlas }\end{array}$ & Total \\
\hline No hay o no encuentra trabajo & 44 & 40 & 49 & 10 & 49 & 39 \\
\hline No está preparado & 25 & 13 & 14 & 2 & 3 & 13 \\
\hline Por discapacidad & 0 & 2 & 3 & 0 & 0 & 1 \\
\hline Está estudiando & 23 & 13 & 20 & 61 & 42 & 30 \\
\hline Falta de cédula o partida de nacimiento & 1 & 17 & 4 & 3 & 2 & 6 \\
\hline No le permiten trabajar & 0 & 5 & 4 & 2 & 2 & 2 \\
\hline $\begin{array}{l}\text { Tiene apoyo familiar o recibe remesas del } \\
\text { exterior }\end{array}$ & 2 & 2 & 1 & 0 & 2 & 2 \\
\hline Espera embarcarse & 3 & 4 & 0 & 5 & 0 & 2 \\
\hline $\begin{array}{l}\text { Quehaceres del hogar o no tiene quien le } \\
\text { cuide a su hijo }\end{array}$ & 2 & 2 & 4 & 10 & 0 & 3 \\
\hline No quiere trabajar & 0 & 2 & 1 & 7 & 0 & 2 \\
\hline
\end{tabular}

Fuente: Elaboración propia basado en datos de FADCANIC 2013.

- ampliar el proceso de cedulación a los municipios, para que las juventudes tenga su documento de identidad;

- ampliar la oferta de centros de desarrollo infantil comunitarios, que permita a jóvenes progenitores tener opción para el cuido de sus vástagos, lo cual les permitirá optar por un trabajo;

- adecuar los horarios de estudio a las necesidades de género de las mujeres. Según la Organización Internacional del Trabajo ser mujer y joven puede constituir una doble fuente de discriminación y son las mujeres jóvenes las que se encuentran con barreras mayores para poder entrar en el mercado laboral y conservar el empleo en los períodos de recesión económica. ${ }^{17}$

\section{Migración y sus causas}

En el estudio queda claro que casi nueve de cada diez adolescentes y jóvenes se irían del país si tuvieran la oportunidad. La mayoría sin diferencias de género dice que migraría para trabajar (41\%) y resolver los problemas económicos de la familia (35\%). Estas cifras coinciden con la apreciación positiva que tiene la juventud a nivel nacional acerca de la migración (ENAJINDH, 2009). En cambio, solo uno de cada cinco migraría por superación personal, y en igual proporción, hombres y mujeres. La juventud del municipio de la Desembocadura es la que menos desea migrar, sobre todo las mujeres, pero aún representan más de la mitad de la población es alta.

Los datos de la Tabla 12 nos dan un panorama sombrío, puesto que la juventud al no encontrar en su país las 


\section{Tabla 12 - Deseo y motivos para emigrar entre adolescentes y jóvenes de cinco municipios de la RAAS (en porcentajes)}

\begin{tabular}{|c|c|c|c|c|c|c|c|c|c|c|c|c|c|}
\hline \multirow[t]{2}{*}{ Deseos o Motivos } & \multicolumn{2}{|c|}{ Bluefields } & \multicolumn{2}{|c|}{ Corn Island } & \multicolumn{2}{|c|}{$\begin{array}{l}\text { Desembocadura } \\
\text { Río Grande }\end{array}$} & \multicolumn{2}{|c|}{ Kukra Hill } & \multicolumn{2}{|c|}{ Pearl Lagoon } & \multicolumn{2}{|c|}{ Total } & \multirow{2}{*}{$\begin{array}{c}\text { Ambos } \\
\text { sexos }\end{array}$} \\
\hline & Hombres & Mujeres & Hombres & Mujeres & Hombres & Mujeres & Hombres & Mujeres & Hombres & Mujeres & Hombres & Mujeres & \\
\hline $\begin{array}{l}\text { Migraría } \\
\text { si tuviera } \\
\text { oportunidad }\end{array}$ & 88 & 91 & 90 & 96 & 82 & 51 & 98 & 86 & 99 & 97 & 92 & 87 & 89 \\
\hline $\begin{array}{l}\text { Se quiere ir para } \\
\text { buscar trabajo }\end{array}$ & 49 & 54 & 42 & 46 & 61 & 30 & 24 & 18 & 33 & 50 & 40 & 43 & 41 \\
\hline $\begin{array}{l}\text { Se quiere ir para } \\
\text { mejorar situación } \\
\text { económica } \\
\text { familiar }\end{array}$ & 30 & 24 & 47 & 47 & 17 & 35 & 59 & 35 & 30 & 23 & 37 & 34 & 35 \\
\hline $\begin{array}{l}\text { Se quiere ir para } \\
\text { estudiar }\end{array}$ & 16 & 18 & 8 & 8 & 22 & 30 & 15 & 35 & 33 & 27 & 20 & 20 & 20 \\
\hline
\end{tabular}

Fuente: Elaboración propia basado en datos de FADCANIC 2013.

condiciones que le permitan una vida digna, debido a las altas tasas de subempleo, pocas oportunidades o incentivos para continuar sus estudios de secundaria, y pero aún, escasas opciones de acceso a carreras técnicas y profesionales, ya tienen decidido emigrar si se le presenta la oportunidad ${ }^{18}$. Esto sería catastrófico para la RACS, ya que el bono demográfico que representa la población adolescente y joven se fugaría; $y$ lo peor es que por los bajos niveles de escolaridad conseguirían trabajos precarios, mal remunerados, con ingresos de supervivencia, sin protección social y vulnerables a la violación de sus derechos humanos en general, y laborales en particular.

\section{OPORTUNIDADES Y AGENTES FACILITADORES}

A pesar de que el panorama expuesto en las tres dimensiones de las fuerzas de la vulnerabilidad nos presentan un panorama poco favorable para muchos adolescentes y jóvenes, es importante destacar que en el estudio también fueron exploradas oportunidades que pueden aprovecharse para cambiar esta realidad, incluyendo algunos factores protectores que es necesario ir fortaleciendo a fin de que las personas reconozcan que cuentan con estos activos que muchas veces pasan desapercibidos y no son muy bien valorados.

De forma general, las actividades deportivas y culturales son las principales posibilidades de recreación y distracción que existen en los municipios. En la percepción de los y las entrevistadas, estas actividades pueden ser utilizadas para desarrollar las habilidades para la vida e ir rompiendo esquemas de género incluso porque hoy los espacios que existen en el deporte son más aprovechados por los hombres jóvenes que por las mujeres jóvenes, y las actividades recreativas y culturales están consolidando estereotipos y relaciones despectivas y hasta abusivas hacia la mujer.

Han sido implementados algunos programas para educar y forjar valores positivos a través de la práctica deportiva y artística que han sido exitosos, los cuales pueden replicarse o mejorar en base a las lecciones aprendidas. En el municipio de la Desembocadura de la Cruz de Rio Grande se reconoce que los programas implementados desde las iglesias son vistos como posibilidades de recreación para la juventud, por lo que también se pueden vincular con otros programas educativos.

18 Además de todas las causas económicas a nivel nacional para migrar, en la Costa Caribe también incide la cultura migratoria, que es especialmente ancestral entre las etnias Creole y Miskita cuya diáspora se extiende por toda la cuenca del Caribe y más allá. 


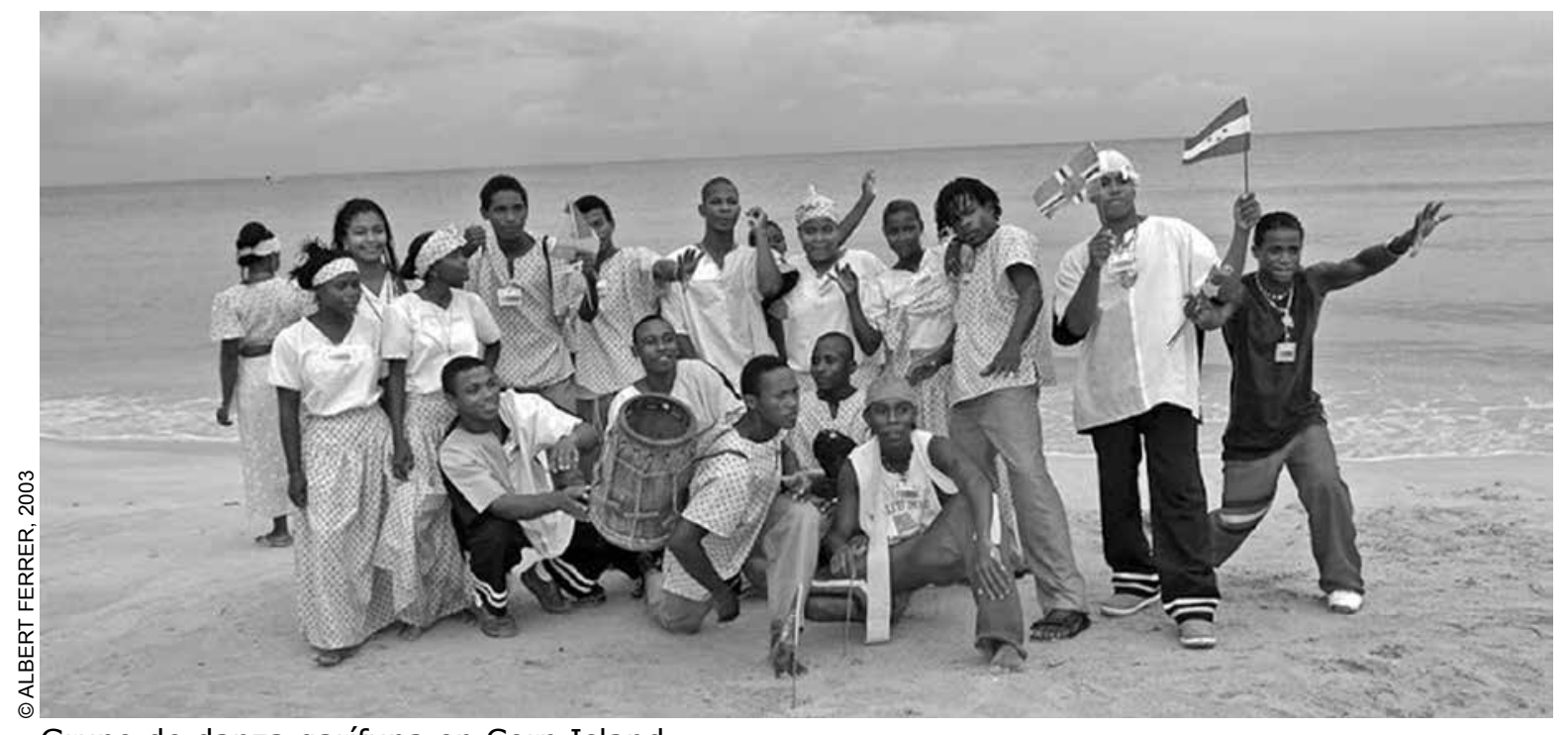

Grupo de danza garífuna en Corn Island.

Se reconoce la existencia del INATEC, pero esta institución de aprendizaje tecnológico tiene carreras y alcance geográfico limitados, que no llenan las expectativas de la juventud. Tomando esto en cuenta se puede promover la creación de más carreras técnicas, retomando las que han propuesto la juventud y progenitores de estos municipios y los grupos de líderes y docentes.

Las comunidades ven potencial económico para los municipios en el mejor aprovechamiento de los recursos naturales (agua, tierra fértil para cultivos, bosques y selvas, productos de la pesca y en el desarrollo de la industria turística, así como en todas las actividades del sector servicio.

De forma específica, los grupos focales identificaron el siguiente potencial económico por municipio:

1. Bluefields: el turismo en la bahía y en los cayos.

2. Corn Island: la pesca y sus derivados para la exportación.

3. Pearl Lagoon: las flores silvestres, las frutas exóticas, los bosques maderables, las buenas tierras y el turismo.

4. Kukra Hill: las buenas tierras y las frutas exóticas.

5. Desembocadura: el turismo, la explotación de la pesca, los bosques y las buenas tierras.

Este potencial económico puede generar oportunidades laborales para la juventud y podrían ser importantes para un desarrollo sustentable de los municipios, pero se necesita que se tecnifiquen o profesionalicen de tal forma que puedan desarrollar las actividades necesarias para generar progreso. Hacia fin, se puede ayudar también a la población juvenil a que visione las maneras en que el diseño y la mecánica, por ejemplo, le pueden agregar valor a los rubros tradicionales.

Se identifica que los diferentes actores comunitarios pueden contribuir para cambiar la situación de sus municipios desarrollando las siguientes actividades concretas:

- Crear grupos de autoayuda.

- Formar promotores jóvenes para trabajo de pares.

- Integrar más a los padres de familia en las actividades escolares.

- Promover la recreación sana rescatando juegos y deportes tradicionales.

- Limitar el consumo de bebidas alcohólicas y los expendios de las mismas, de forma multisectorial.

- Implementar el emprendedurismo juvenil a partir de la conformación de pequeñas empresas de servicios o de producción.

- Ofrecer becas de estudio para las personas más necesitadas.

- Ofertar educación primaria, secundaria, técnica y superior, de acuerdo a las necesidades planteadas por jóvenes y tomando en cuenta sus diversidades - jóvenes que trabajan, jóvenes que son madres, jóvenes en rezago escolar, jóvenes indígenas y afrodescendientes.

- Identificar programas que han sido exitosos, tales como programas de educación entre pares sobre sexualidad impulsados por la alcaldía y organizaciones juveniles de la región; ampliar el programa Educación para el Éxito de FADCANIC y USAID a sectores con mayor vulnerabilidad. 


\section{Recomendaciones}

- Promover una visión diferente de la juventud como protagonista de su propio desarrollo y de su comunidad y no solo como juventud problema y abrir oportunidades que les permita cumplir sus anhelos y aspiraciones.

- Desarrollar y expandir programas que contribuyan a superar las barreras que impiden el acceso de jóvenes en situación de desventaja económica para poder mejorar las oportunidades educativas.

- Instalar carreras técnicas y de técnico medio en los municipios más urgidos de este apoyo, como Desembocadura de Río Grande. Así también debería gestionarse la demanda laboral proyectada en las empresas de la región, para una elección y organización de carreras técnicas.

- Replicar la experiencia del Programa Educación para el Éxito, que es una experiencia exitosa de la región, implementando nuevas oportunidades de carreras técnicas vinculadas con la agricultura e identificando los lugares más apropiados, así como carreras para una mejor explotación de los recursos del mar, del agua y de las frutas exóticas.

- Combinar la educación formal con programas para desarrollar competencias para la vida y el desarrollo de habilidades deportivas, así como un programa de rescate de las tradiciones culturales de los pueblos que permita a jóvenes en riesgo involucrarse en grupos de interés según los talentos que tengan o descubran.

- Establecer comunidades a priorizar dentro de los municipios, sobre todo aquellas en donde han sido encontrados jóvenes con mayores desventajas, brindando alternativas de transporte y horarios adecuados a sus necesidades para facilitar su acceso a diferentes alternativas de capacitación, educación y recreación.

- Organizar, paralelamente al proyecto educativo para jóvenes en riesgo, un programa de padres de familia, líderes, docentes y autoridades locales, de modo que toda la comunidad se involucre en la gestión cuyo fin se dirige al desarrollo socioeconómico y sociocultural, mediante la reinserción de jóvenes en el sistema educativo. Este podría ser un programa de capacitaciones en serie, con colaboración articulada a través de alianzas institucionales con INAFOR, MINSA, SINAPRED, la policía y otros.

- Las organizaciones comunales requieren de apoyo sobre temas de gobernabilidad. Impulsar el desarrollo de procesos de revitalización cultural como elemento esencial para el empoderamiento de agentes comunitarios y la sostenibilidad de sus iniciativas.

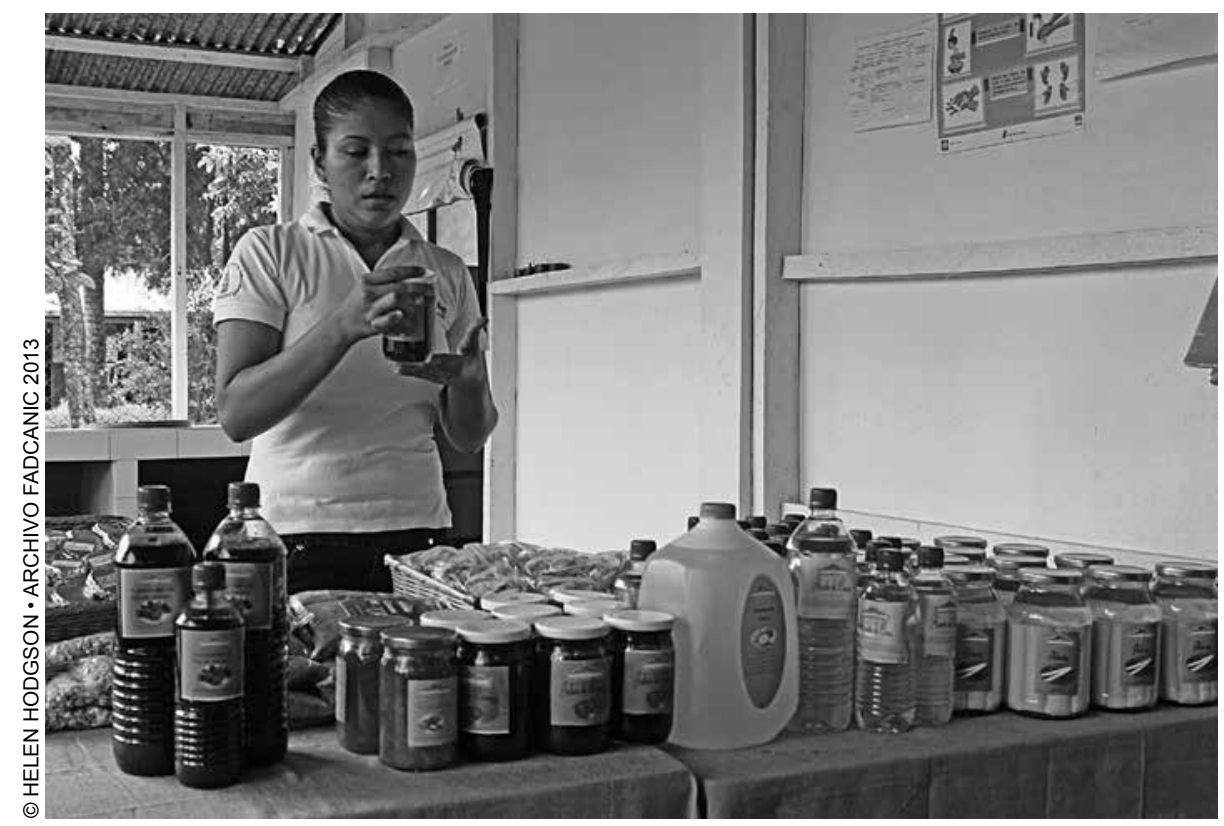

Productos procesados en el Centro de Desarrollo Agroforestal en Wawashang. 


\section{BIBLIOGRAFÍA}

Brearley, P. C. 1982. Risk in Social Work. London: Routledge and Kegan Paul.

Caputo, Luis, y Palau, Marielle. 2004. Resultados del Estudio Juventud y exclusión social. Conceptos, hipótesis y conocimientos interpretativos de la condición juvenil. Base Investigaciones Sociales. Asunción.

CELADE 2001. Rodríguez J. Informe vulnerabilidad y grupos vulnerables: un marco de referencia conceptual mirando a jóvenes.

Cortázar, Juan. 1997. La juventud como fenómeno social. Pistas teóricas para comprender el periodo juvenil en el Perú. Lima, Universidad Peruana Cayetano Heredia.

Cranshaw, Martha I, Abelardo Morales. 1998. Mujeres Adolescentes y Migración entre Nicaragua y Costa Rica, FLACSO, Programa Mujeres Adolescentes, San José.

FADCANIC 2013. Martínez, E. Informe Final Estudio de situación socioeducativa-económica de la juventud en contexto de vulnerabilidad en cinco municipios de la Región Autónoma del Atlántico Sur.

Giddens, Anthony. 1994. Modernidad e identidad del yo. El yo y la sociedad en la época contemporánea, trad. de José Luis Gil Aristu, Península, Barcelona.

Gobierno Regional Autónomo Atlántico Sur. 2009. Agenda de Adolescentes y Jóvenes de la Región Autónoma del Atlántico Sur.

INEC. 2005. VIII Censo Nacional de Población y IV de Vivienda Mapa de Pobreza Extrema Municipal por el Método de Necesidades Básicas.

INIDE 2012. Encuesta Nicaragüense de Demografía y Salud 2011/12, Informe preliminar, pág. 44-45

López Santos Dalgis. 2012, Reflexiones teóricas sobre Identidad Juvenil. Centro de Estudios Sobre la Juventud. Cuba.

MINSA, SILAIS, RAAS, 2009. Sistema Nacional de Estadísticas.

OEA, CICAD. 2006. Primer estudio comparativo sobre uso de drogas en población escolar secundaria.

OMS. 2008. Informe sobre la epidemia mundial de tabaquismo, 2008 - Plan de medidas MPOWER.

PNUD. 2009. Informe de Desarrollo Humano Nicaragua 2005 de la Costa Caribe de Nicaragua: ¿Nicaragua asume su diversidad?

2009, Encuesta Nacional de Juventud para el Informe Nacional de Desarrollo Humano.

2011. Informe Nacional sobre Desarrollo Humano 2011. Las juventudes construyendo Nicaragua.

Sen, A.K. 1985. Well-being, Agency and Freedom: The Dewey Lectures 1984, The Journal of Philosophy, 82 (4), pp. $169-221$.

Suárez, E.N. y Krauskopf, D. 1992. El enfoque de Riesgo y su Aplicación a las Conductas en la Adolescencia. Una Perspectiva Psicosocial. En prensa, OPS. Washington.

UNFPA. 2013. Estudio sobre situación de adolescentes y jóvenes en 43 municipios de Nicaragua. Derechos, convivencia, participación y salud sexual y reproductiva, Managua.

White, L. 2000. The Family as a Social Organization: Key Ideas for the Twenty-first Century, Contemporary Sociology, Volumen 29, No 3.

Weinstein, J. 1992. Riesgo Psicosocial en jóvenes. PREALC. Santiago de Chile. 